\title{
Hybrid structural control using magnetorheological dampers for base isolated structures
}

\author{
Sk Faruque Ali and Ananth Ramaswamy ${ }^{1}$ \\ Department of Civil Engineering, Indian Institute of Science, Bangalore-560012, India \\ E-mail: sk.faruque.ali@gmail.com and ananth@civil.iisc.ernet.in
}

Received 25 September 2008, in final form 26 January 2009

Published 6 April 2009

Online at stacks.iop.org/SMS/18/055011

\begin{abstract}
In this paper two nonlinear model based control algorithms have been developed to monitor the magnetorheological (MR) damper voltage. The main advantage of the proposed algorithms is that it is possible to directly monitor the voltage required to control the structural vibration considering the effect of the supplied and commanded voltage dynamics of the damper. The efficiency of the proposed techniques has been shown and compared taking an example of a base isolated three-storey building under a set of seismic excitations. Comparison of the performances with a fuzzy based intelligent control algorithm and a widely used clipped optimal strategy has also been shown.
\end{abstract}

(Some figures in this article are in colour only in the electronic version)

\section{Introduction}

The destruction caused by seismic events over centuries across the world have clearly demonstrated the importance and the urgency of mitigating the effect of such natural hazards on structures. One of the biggest challenges structural engineers face today is finding more effective means for protecting structures and their contents from the damaging effects of dynamic hazards such as strong earthquakes. The idea of using control systems to dissipate, counteract, or isolate vibration energy has been identified as one promising approach in this direction (see [1]).

A control system can be classified as either passive, active, hybrid, or semi-active based on the level of energy required and the type of control devices employed. Among these systems, the semi-active approach has recently received considerable attention, because it offers significant adaptability of active systems without large power requirements and is as reliable as passive systems. Rapid-response, fail-safe, low power requirement, simple interfaces between electronic controls and mechanical systems are some characteristics of magnetorheological (MR) devices that have attracted significant research interest for using them as semi-active control devices in applications of vibration mitigation $[1,2]$.

\footnotetext{
1 Author to whom any correspondence should be addressed.
}

In particular, it has been found that MR dampers can be designed to be very effective vibration control actuators. In civil engineering, MR damper applications have mainly centred around the structural vibration control under wind and earthquake excitations [2,3]. The automotive industry has been interested in developing applications of these materials, for example, for engine mounts, shock absorbers, clutches, and seat dampers [4].

Magnetorheological dampers are nonlinear devices due to their inherent hysteretic damping characteristics. Their nonlinear hysteretic characteristics are varied (monitored) by changing the input voltage to the damper. The nonlinear hysteretic behaviour and voltage monitoring make the design of suitable control algorithms, that can provide a smooth change in voltage, an interesting and challenging task. The force predicted by the available control algorithms is mapped to equivalent voltage and then fed into the damper. This inverse mapping of force to voltage makes the choice and development of control algorithms more complicated. Available semi-active control algorithms in the literature use an 'on-off' or 'bangbang' strategy for MR applications. The 'on-off' nature of these algorithms neither provides a smooth change in MR damper voltage input nor does it consider all possible voltage values within its full range [5].

A wide range of theoretical and experimental studies has been performed to assess the efficacy of MR dampers as 
semi-active devices [5,6]. In one of the first examinations, Karnopp et al [4] proposed a 'skyhook' damper control algorithm for a vehicle suspension system and demonstrated that this system offers improved performance over a passive system when applied to a single-degree-of-freedom (SDOF) system. Thereafter, bang-bang [7] and Lyapunov function based approaches have been studied and reported $[8,9]$. Dyke et al [2] proposed a clipped optimal control algorithm based on acceleration feedback for the MR damper. In this approach, a linear optimal controller, combined with a force feedback loop, was designed to adjust the command voltage of the MR damper. The command signal was set at either zero or the maximum level depending on how the damper force compared with the target optimal control force. The target optimal control can be obtained from the $\mathrm{H}_{2} / \mathrm{LQG}$ (linear quadratic Gaussian) [2] and Lyapunov based methods [9].

The main disadvantage of the clipped optimal strategy is that it tries to change the voltage of the MR damper directly from 0 to its maximum value (in the present case $5 \mathrm{~V}$ ), without any intermediate voltage supply. This makes the controller a sub-optimal one. This swift change in voltage led to a sudden rise in the external control force which increases the system responses [3]. Moreover, the clipped optimal strategy needs the measurement of the force the damper provides. Here, the mathematical information regarding the structure is used for the calculation of the numerically obtained control forces to compare with the experimentally obtained damper force. Based on the compared result an on-off strategy is used to keep the damper input voltage to zero or to change it to maximum, and vice versa. Therefore, there is a need for control algorithms which can change the MR damper voltage, slowly and smoothly, such that all voltage values between maximum and zero voltage can be covered, based on the feedback from the structure.

In this context various intelligent methods (neural controllers [10] and non-adaptive and adaptive fuzzy controllers [3]) have been tried in which the damper monitoring voltage is directly set based on system feedback. Ali and Ramaswamy [3] provide a comparison of adaptive, non-adaptive, and Lyapunov based clipped optimal strategies for a nonlinear base isolated benchmark building.

One main disadvantage of the intelligent controllers is that they are mostly problem oriented, and therefore a more general approach to voltage monitoring still remains unexplored. Furthermore, neither the intelligent controllers nor the model based clipped optimal controllers consider the effect of the input voltage on the commanded voltage dynamics (the voltage that actually goes to the coil to create a magnetic flux). The dynamics matters less when the supplied voltage is a constant and does not vary. When the supplied voltage to the MR damper is varied based on the system responses and desired performance of the system, the difference in the supplied voltage and the commanded voltage plays a crucial role [11].

In this paper, development of two model based control algorithms for voltage monitoring of MR dampers is reported. The first control algorithm is based on a dynamic inversion (DI) strategy, in which DI has been used to track the control force prescribed by a state feedback control algorithm. The second algorithm is based on an integrator backstepping technique. A comparison with the optimal fuzzy logic control (FLC) [3] and the clipped optimal algorithm [2] is also presented. Section 2 provides details of the MR damper mathematical model used in the present study. Control strategies considered are reported after that. Finally, the results of the proposed algorithms applied to a base isolated building are presented, along with a comparison with the results from other algorithms.

\section{Magnetorheological damper}

An MR damper consists of a hydraulic cylinder containing MR fluid that, in the presence of a magnetic field, can reversibly change from a free-flowing, linear viscous fluid to a semi-solid with controllable yield strength in a fraction of a second. An MR fluid is a suspension of micron-sized magnetically soft particles in a carrier liquid (such as water, mineral or synthetic oil), that exhibits dramatic changes in rheological properties. Under the influence of a magnetic field these particles arrange themselves to form very strong chains of fluxes [12,13]. Once aligned in this manner, the particles are restrained from moving away from their respective flux lines and act as a barrier preventing the flow of the carrier fluid.

An RD-1005-3 MR damper [14], manufactured by Lord ${ }^{\circledR}$ Corporation, has been used for the study. The damper is $208 \mathrm{~mm}$ long in its extended position, and $155 \mathrm{~mm}$ in the fully compressed position. The damper can provide a stroke of $\pm 25 \mathrm{~mm}$. The input voltage can be varied to a maximum of $2.5 \mathrm{~V}$ (continuous supply) and $5 \mathrm{~V}$ (intermittent supply). In this paper, the simple Bouc-Wen model [15] has been explored to characterize the MR damper. The force $u(t)$ provided by an MR damper as predicted by the Bouc-Wen model is given by [15]

$$
\begin{gathered}
u(t)=k_{0} x_{\mathrm{mr}}(t)+c_{0} \dot{x}_{\mathrm{mr}}(t)+\alpha z_{\mathrm{mr}}(t, x) \\
\dot{z}=-\gamma\left|\dot{x}_{\mathrm{mr}}\right| z_{\mathrm{mr}}\left|z_{\mathrm{mr}}\right|^{n-1}-\beta \dot{x}_{\mathrm{mr}}\left|z_{\mathrm{mr}}\right|^{n}+A \dot{x}_{\mathrm{mr}}
\end{gathered}
$$

where $x_{\mathrm{mr}}$ is the displacement at the damper location; $z_{\mathrm{mr}}$ is the evolutionary variable, and $\gamma, \beta, n, A$ are parameters controlling the linearity in the unloading and the smoothness of the transition from the pre-yield to the post-yield region.

The functional dependence of the device parameters on the command voltage $v_{\mathrm{c}}$ is expressed as

$$
\begin{gathered}
\alpha\left(v_{\mathrm{c}}\right)=\alpha_{\mathrm{a}}+\alpha_{\mathrm{b}} v_{\mathrm{c}} ; \quad c_{0}\left(v_{\mathrm{c}}\right)=c_{0 \mathrm{a}}+c_{0 \mathrm{~b}} v_{\mathrm{c}} ; \\
k_{0}\left(v_{\mathrm{c}}\right)=k_{0 \mathrm{a}}+k_{0 \mathrm{~b}} v_{\mathrm{c}} .
\end{gathered}
$$

The six parameters $\left(c_{0}, k_{0}, \alpha, \gamma, \beta, A\right)$ are estimated on the basis of minimizing the error between the model-predicted force $(u)$ and the force obtained in the experiment (details are given in [16]). In addition, the resistance and inductance present in the circuit introduce dynamics into this system. This dynamics has been accounted for by the first-order filter on the control input given by

$$
\dot{v}_{\mathrm{c}}=-\eta\left(v_{\mathrm{c}}-v_{\mathrm{a}}\right)
$$

where $\eta$ is the time constant associated with the first-order filter and $v_{\mathrm{a}}$ is the voltage supplied to the current driver. 
Table 1. MR damper parameter values.

\begin{tabular}{llll}
\hline Parameter & Value & Parameter & Value \\
\hline$\alpha_{\mathrm{a}}$ & $1.9504 \times 10^{5} \mathrm{~N} \mathrm{~m}^{-1}$ & $\alpha_{\mathrm{b}}$ & $3.9334 \times 10^{5} \mathrm{~N} \mathrm{~m}^{-1} \mathrm{~A}^{-1}$ \\
$\mathrm{c}_{0 \mathrm{a}}$ & $8.666 \times 10^{2} \mathrm{~N} \mathrm{~s} \mathrm{~m}^{-1}$ & $\mathrm{c}_{0 \mathrm{~b}}$ & $4.1452 \times 10^{3} \mathrm{~N} \mathrm{~s} \mathrm{~m}^{-1} \mathrm{~A}^{-1}$ \\
$k_{0 \mathrm{a}}$ & $7.5140 \times 10^{2} \mathrm{~N} \mathrm{~s} \mathrm{~m}^{-1}$ & $k_{0 \mathrm{~b}}$ & $3.4597 \times 10^{3} \mathrm{~N} \mathrm{~s} \mathrm{~m}^{-1} \mathrm{~A}^{-1}$ \\
$\eta$ & $190 \mathrm{~s}^{-1}$ & $n$ & 2 \\
$\gamma$ & 2.85 & $\beta$ & 5.420 \\
$A$ & 12.26 & & \\
\hline
\end{tabular}

This we refer to as supplied to commanded current dynamics. This dynamics has not been considered in algorithms that are available in the literature.

To determine the parameters of the Bouc-Wen model, sinusoidal testing of an MR damper with a set of amplitudes and frequencies of excitations and at varied input voltage has been considered (details of the experiments are given in [16]). A matrix of frequencies $(0.1,0.25,0.50,1.0,1.5,2.0,2.5$, $3.0 \mathrm{~Hz})$, amplitude $(2.5,5.0,10.0,15.0,20.0 \mathrm{~mm})$, and current supply $(0.0,1.0,1.5,2.0,2.5 \mathrm{~A})$ formed the test programme. The six parameters $\left(c_{0}, k_{0}, \alpha, \gamma, \beta, A\right)$ are optimized on the basis of minimizing the error between the model-predicted force $\left(f_{\mathrm{c}}\right)$ and the force $(F e)$ obtained in the experiment. The parameter $n$ is taken to be 2 and the other parameters are optimized. The error in the model is represented by the objective function $J$, given by

$$
J=\frac{\sum_{i=1}^{N}\left(f_{\mathrm{c} i}-F e_{i}\right)^{2}}{\sum_{i=1}^{N} F e_{i}^{2}}
$$

where $N$ is the number of points in the experimental data. Optimum values for the six parameters are obtained using the lsqcurvefit (least square curve fitting) algorithm available in the MATLAB ${ }^{\circledR}$ optimization toolbox [17] for nonlinear curve fitting. A separate curve fitting is carried out based on the obtained optimal values of $\left(c_{0}, k_{0}, \alpha\right)$ for voltage dependence [16].

For the present study on seismic vibration mitigation application of the MR damper, the damper parameters obtained are given in table 1 (details in [16]). Figure 1 shows the comparison of analytical and experimental curves for varied voltage inputs at $10 \mathrm{~mm}$ amplitude and $1 \mathrm{~Hz}$ sinusoidal excitation frequency.

\section{Control strategies}

The present paper develops two nonlinear control algorithms to monitor the MR damper voltage for structural vibration control applications. The performances of the proposed algorithms are compared with that of widely used clipped optimal strategy and optimal fuzzy logic control. Section 3.1 documents some details about the existing algorithms and develops the proposed nonlinear algorithms. The clipped optimal control strategy has been described here for the sake of completeness and also to motivate the development of the two model based controllers described in this paper.

\subsection{Clipped optimal control}

The clipped optimal control algorithm has been proposed by Dyke et al [2]. It is currently the most widely used algorithm for MR damper control. This strategy consists of a bang-bang (on-off) type of controller that causes the damper to generate a desirable control force which is determined by an 'ideal' active controller (in state feedback form). As shown in the schematic diagram in figure 2(a), a force feedback loop is used to produce the desired control force $\left(f_{\mathrm{d}}\right)$, which is determined by a linear optimal controller $\left(\mathbf{K}_{k}(s)\right)$, based on the measured structural responses $(y)$ and the measured damper force $\left(f_{\mathrm{c}}\right)$ at the current time.

The damper force is then calculated by

$$
f_{\mathrm{d}}=L^{-1}\left\{-\mathbf{K}_{k}(s) L\left(\frac{y}{f_{\mathrm{c}}}\right)\right\}
$$

where $L(\cdot)$ is the Laplace transform operator. The linear controller is usually obtained using $\mathrm{H}_{2}$ or LQG strategies. The applied voltage, $v_{\mathrm{a}}$, to the MR damper can be commanded and not the damper force; hence when the actual force being generated by the MR damper, $f_{c}$, equals the desirable force, $f_{\mathrm{d}}$, the voltage applied remains the same. Again, when the magnitude of the force $f_{\mathrm{c}}$ is smaller than the magnitude of $f_{\mathrm{d}}$ and both forces have the same sign, then the voltage applied is set to its maximum level, to increase the damper force. Otherwise, the voltage is set to zero.

This algorithm for selecting the voltage signal is graphically represented in figure 2(b) and described by

$$
v_{\mathrm{a}}=v_{\max } H\left(f_{\mathrm{d}}-f_{\mathrm{c}}\right) f_{\mathrm{c}}
$$

where $v_{\max }$ is the voltage level associated with the saturation of the magnetic field in the MR damper, and $H(\cdot)$ is the Heaviside step function operator.

The performance of the clipped optimal control algorithm has been evaluated through numerical simulations [2] and demonstrated for multiple MR dampers in [18]. A comparison with other algorithms has also been presented in [19]. In all cases the clipped optimal controller has been found to satisfactorily reduce the structural responses and outperform passive control strategies.

The main disadvantage of the clipped optimal strategy is that it tries to change the voltage of the MR damper from zero to its maximum value, which makes the control force suboptimal. Moreover, sometimes this swift change in voltage and therefore sudden rise in external control force increases the system responses, which may lead to an inelastic response of the structure. Therefore there is, indeed, a need for better 

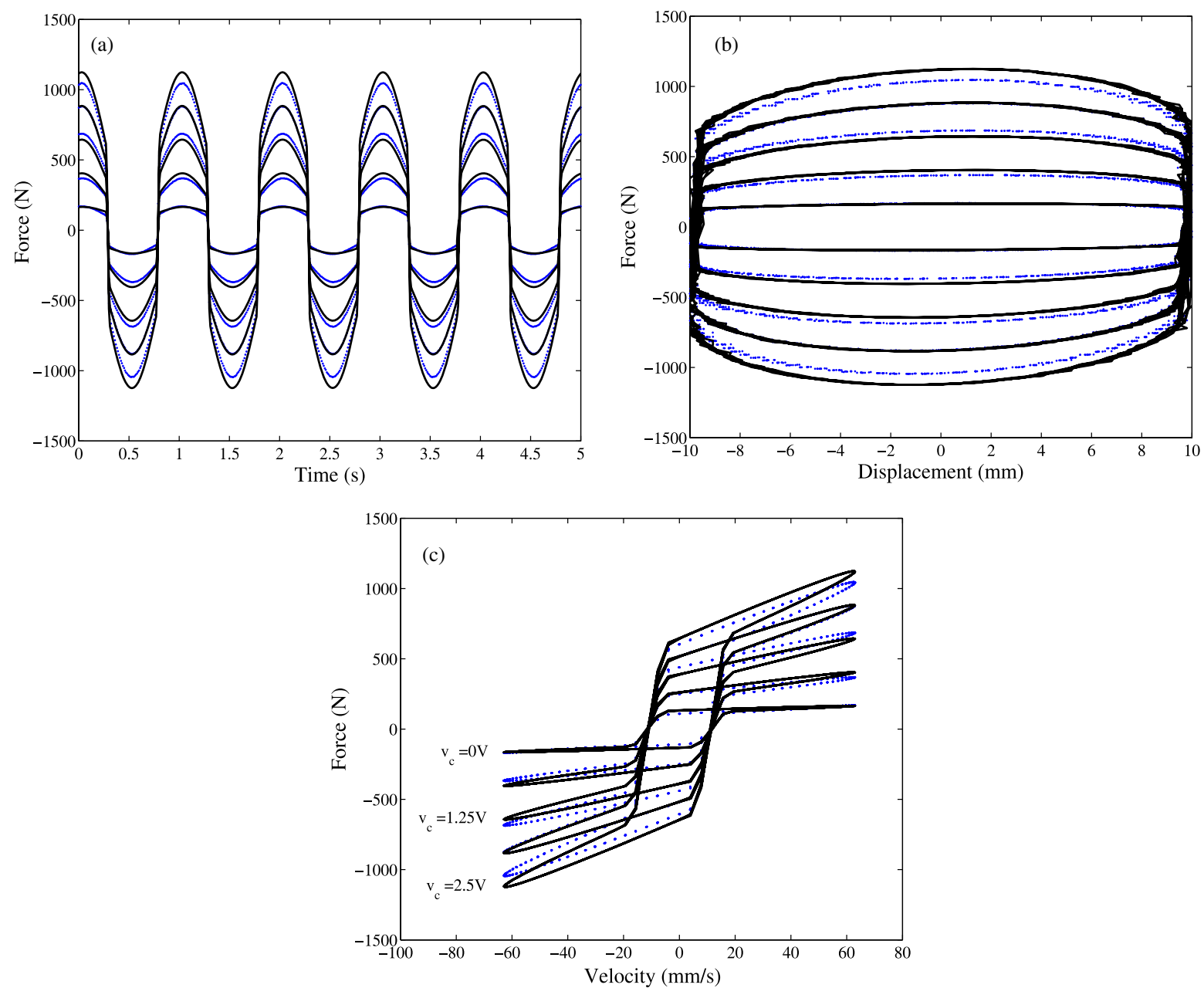

Figure 1. Comparison of the experimental $(\cdots)$ and analytical ( - models: variable current $\left(x_{\mathrm{a}}=10 \mathrm{~mm}, \omega=1.0 \mathrm{~Hz}\right)$. (a) Force time history. (b) Force-displacement. (c) Force-velocity.

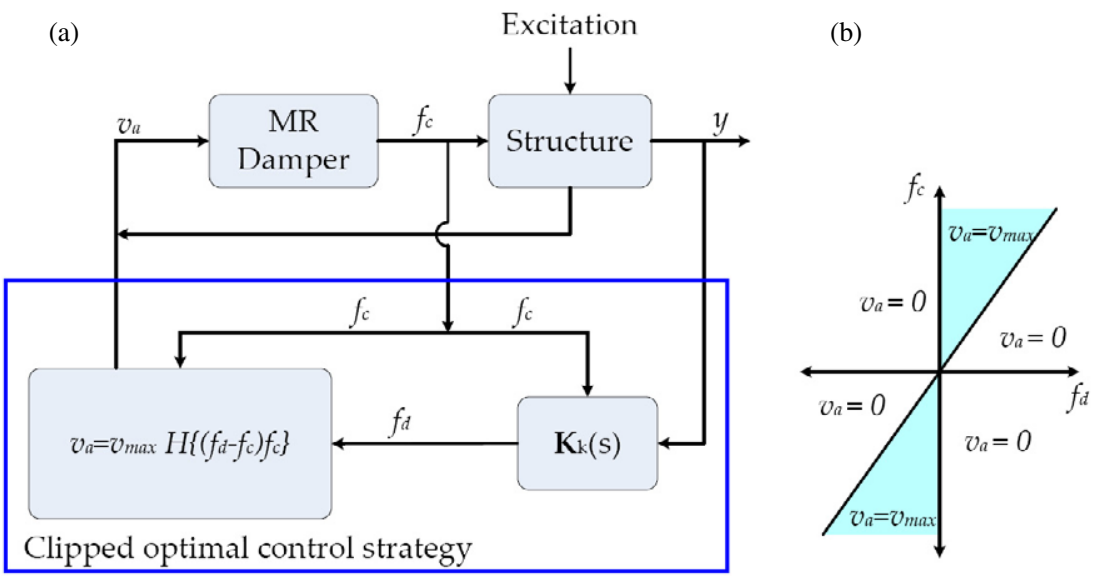

Figure 2. Clipped optimal algorithm [2]. (a) Block diagram of clipped optimal algorithm. (b) Graphical representation.

control algorithms that can change the MR damper voltage slowly and smoothly, such that all voltages between maximum and zero voltage can be covered based on the feedback from the structure. In addition, the algorithm needs to consider the dynamics between the applied voltage and the commanded voltage (given by equation (3)). Intelligent control algorithms have been used to solve the first of the above-mentioned constraints but the inclusion of supplied to commanded voltage dynamics has not been addressed.

\subsection{Optimal fuzzy logic control}

As an alternative to conventional model based control theory, intelligent control allows the resolution of imprecise or 


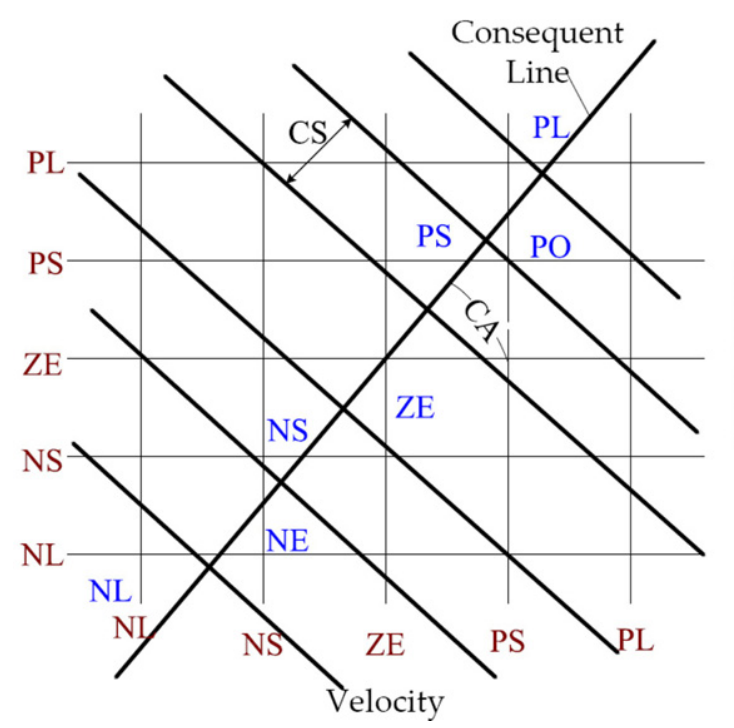

Figure 3. Optimal rule base design.

uncertain information in the structural model and the damper model. In the present paper we propose an optimal fuzzy logic based intelligent controller. It maps the nonlinear input-output relation effectively and also handles the hysteretic behaviour of structures under earthquake loads with ease.

The FLC has two input variables, namely, acceleration and velocity, at the damper location and provides MR damper voltage as an output. The input/output variables are normalized over the UOD (universe of discourse) of $[-1,1]$. The input variables range their respective UODs using five equally spaced 'gbell' shaped membership functions (MFs) $(\mathrm{NL}=$ negative large, $\mathrm{NS}=$ negative small, $\mathrm{ZE}=$ zero, $\mathrm{PS}=$ positive small, $\mathrm{PL}=$ positive large). Seven equally spaced 'gbell' shaped MFs have been used to define the output voltage $(v(t) \in[0,1]),(\mathrm{PO}=$ positive; $\mathrm{NE}=$ negative MFs are extra). The extreme MFs for input variables are kept unbounded in the respective positive (s-shaped) and negative (z-shaped) UOD. This is done to consider the values of input that are outside the range of the UOD. It is to be noted that the output contains negative values, which is done to keep symmetry about zero in UOD.

Furthermore, the voltage $(v(t))$ output from the FLC, unlike the clipped optimal, can take any value in the range $[0,1]$, and therefore covers the full voltage range available for the damper [3]. In the process, the voltage switch is gradual and does not jump between zero and maximum values as in Lyapunov or LQG clipped optimal control cases. A microgenetic algorithm ( $\mu$-GA) [20] is used to optimize the fuzzy logic control parameters like the input-output MFs, scaling gains, and the fuzzy rule base [3].

For the GA used in this study, each chromosome represented a complete FLC as defined by [17] fuzzy inference system. The rule base is modified using a geometric approach keeping the symmetry in the rule base structure. The geometric approach requires fewer optimization variables and thereby reduces the chromosome length. This reduces the computational overhead of the optimization scheme.

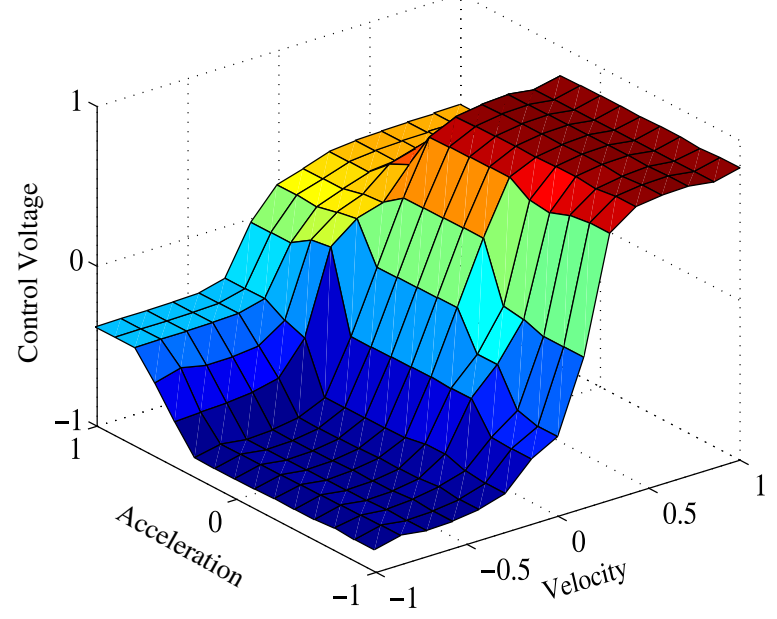

Figure 4. Optimal fuzzy rule base.

The idea behind the geometric approach is shown in figure 3. The consequent space (space spanned by the output MFs) is overlaid upon the 'premise coordinate system' (space spanned by the input MFs) and is in effect partitioned into seven non-overlapping small regions. Each region represents a consequent fuzzy set. The design of the optimal rule base is achieved using the consequent line as shown in figure 3 . The line is made pivotal on premise zero-zero position (i.e., both inputs being zero) and it is free to rotate over the consequent space. Each specific position of the consequent line provided a new rule base. Therefore the slope of the consequent line (CA) is encoded as an optimization variable. It is to be noted that the rule base remains symmetrical whatever the position (orientation) of the consequent line. The rule base is then extracted by determining the consequent region in which each premise combination point lies. Next a consequentregion spacing (CS) is encoded to define the distance between consequent points along the consequent line. These two optimization variables (CA and CS) provides optimal rule selection.

The MF properties altered by the GA are MF shape, MF centre shift, and MF slope at 0.5 membership grade. Details of the $\mu$-GA encoding of the optimal FLC have been reported in $[3,11,20]$. For the present study an off-line trained FLC has been adopted. The off-line training is carried out by providing an initial base displacement of $0.025 \mathrm{~m}$ and then allowing the hybrid system to come to rest. The FLC that minimizes the following cost function is adopted for the study.

$$
J_{g a}=\left\|\frac{x_{\mathrm{b}}}{x_{\mathrm{b}_{\mathrm{unc}}}}\right\|+\left\|\frac{\ddot{x}_{\mathrm{b}}}{\ddot{x}_{\mathrm{b}_{\mathrm{unc}}}}\right\| .
$$

The above cost function considers minimization ( $\mathrm{L}_{2}$ norm) of the ratio of base displacement $\left(x_{\mathrm{b}}\right)$ with controller and base displacement $\left(x_{\mathrm{b}_{\text {unc }}}\right)$ without controller, at the same time minimizing the corresponding ratio of acceleration norms. Figure 4 shows the rule base surface obtained from the optimization process. 


\subsection{Dynamic inversion based control}

Dynamic inversion (DI) control methodology has gained popularity among control engineers in recent years and has been applied to different types of aircraft applications [21]. DI is a control synthesis technique by which existing deficient or undesirable dynamics are nullified and replaced by designerspecified desirable dynamics [21]. This tuning of system dynamics is accomplished by a careful algebraic selection of a feedback function. It is for this reason that the DI methodology is also called the feedback linearization technique. Details of feedback linearization and DI are available in [22].

Like all other model based systems, a fundamental assumption in this approach is that the plant dynamics are perfectly modelled, and therefore can be cancelled exactly by the feedback functions. Here also we assume that no uncertainty is involved in the plant dynamics and parameters. In this paper, DI is used for a two-stage controller formulation. The first stage contains a primary controller which provides the force required to obtain a desired closed loop response of the system. Thereafter, DI is used to predict the required MR damper voltage such that it can track the force prescribed by the primary controller. Figure 5 shows the schematic diagram of the proposed two-stage controller incorporating dynamic inversion as the second-stage controller. Therefore the overall control scheme forms a new two-stage stabilizing state feedback control design approach.

To formulate the proposed two-stage controller let us consider a system in state space form as given by

$$
\dot{X}=A X+B u+E \ddot{x}_{\mathrm{g}}
$$

where $X \in \mathbb{R}^{n}$ is the state of the system, $u \in \mathbb{R}^{1}$ is the damper force, and $\ddot{x}_{\mathrm{g}}$ is the input excitation to the system. $A \in \mathbb{R}^{n \times n}, B \in \mathbb{R}^{n \times 1}$, and $E \in \mathbb{R}^{n \times 1}$ are the system state matrix, controller location vector, and influence vector for support excitation, respectively.

$$
f_{\mathrm{c}}(t)=c_{0} \dot{x}_{\mathrm{mr}}+k_{0} x_{\mathrm{mr}}+\alpha z_{\mathrm{mr}}
$$

where $f_{\mathrm{c}}$ is the MR damper force represented as $u(t)$ in equation (8). The damper parameters for seismic application are tabulated in table 1. For simplification, it is assumed that the system is perfectly observable, controllable, and the all states are measurable.

3.3.1. Primary controller design. An LQR (linear quadratic regulator) control algorithm is considered as the first-stage or primary controller. The LQR algorithm is designed to obtain the optimal force required to minimize the cost function defined as

$$
J_{1}=\lim _{\tau \rightarrow \infty} \frac{1}{\tau}\left[\int_{0}^{\tau}\left\{(X)^{\mathrm{T}} Q(X)+u^{\mathrm{T}} R u\right\} \mathrm{d} t\right]
$$

where $Q$ and $R$ are weighting matrices used to appropriately weight the states and calculate the controller force required. Minimization of the performance index in equation (10) with the system dynamics (equation (8)) as a constraint gives a state feedback form of the control force required [23].

$$
f(t)=-K_{\mathrm{g}} X
$$

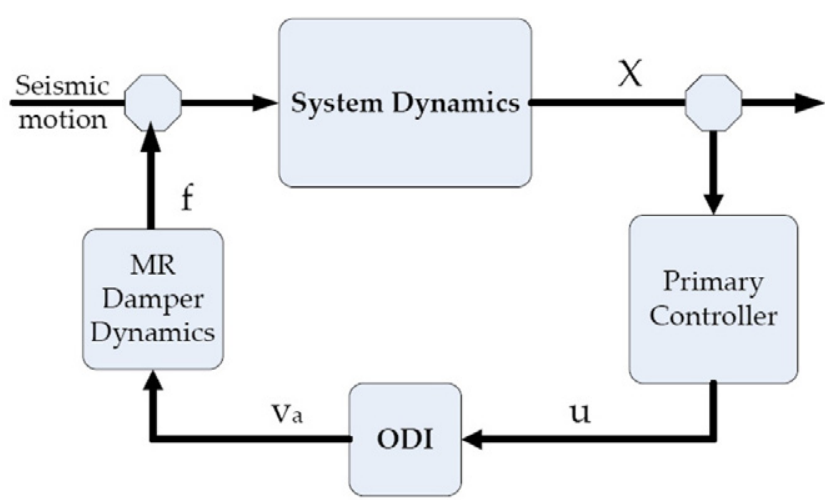

Figure 5. Schematic diagram of a two-stage dynamic inversion controller.

where $K_{\mathrm{g}}$ is the feedback gain matrix and $X$ the measured states (the states are assumed to be perfectly measured). The feedback gain $\left(K_{\mathrm{g}}\right)$ has been obtained using the lqr function available with the Control Toolbox ${ }^{\circledR}$ in MATLAB [17].

Once the state feedback form of the optimal control force has been obtained, it is necessary to compute the voltage to be supplied to the MR damper such that the MR damper provides similar control force. A dynamic inversion based approach is adopted to obtain a closed form solution of the input voltage to be supplied to the MR damper to obtain the desired optimal force.

3.3.2. Secondary controller design (dynamic inversion). The secondary controller is designed with a goal to minimize the error between the primary controller and the control force supplied by the MR damper in an $\mathrm{L}_{2}$ normed sense. To meet the aforementioned goal, an error term is defined as

$$
e=\frac{1}{2}\{u(t)-f(t)\}^{2}
$$

The error dynamics is formulated to minimize the error $(e)$ between the primary controller force and the damper force.

$$
\begin{gathered}
\dot{e}+k_{e} e=0 \\
\{\dot{u}(t)-\dot{f}(t)\}\{u(t)-f(t)\}+\frac{k_{e}}{2}\{u(t)-f(t)\}^{2}=0 .
\end{gathered}
$$

In equations (13), $k_{e}>0$ serves as a gain. For a better physical interpretation, one may choose it as $k_{e}=\frac{1}{\tau_{\mathrm{c}}}$, where $\tau_{\mathrm{c}}>0$ serves as a 'time constant' for the error $e(t)$ to decay. The stability of the controller and its tracking efficiency is defined by the gain $k_{e}$. It should be noted that equations (13) contain the dynamics of the primary control force $(\dot{f})$ and the force provided by the MR damper $(\dot{u})$. Equation (11) provides $\dot{f}(t)$ and equation (9) provides $\dot{u}(t)$, which are given in equations (14) and (15), respectively.

$$
\begin{aligned}
\dot{f}(t) & =-K_{\mathrm{g}} \dot{X} \\
\dot{u}(t) & =\left(C_{0 \mathrm{a}} \ddot{x}_{\mathrm{mr}}+K_{0 \mathrm{a}} \dot{x}_{\mathrm{mr}}+\alpha_{\mathrm{a}} \dot{z}_{\mathrm{mr}}\right) \\
& -\left(C_{0 \mathrm{~b}} \dot{x}_{\mathrm{mr}}+K_{0 \mathrm{~b}} x_{\mathrm{mr}}+\alpha_{\mathrm{b}} z_{\mathrm{mr}}\right) \eta \hat{v}_{\mathrm{c}} \\
& +\left(C_{0 \mathrm{~b}} \ddot{x}_{\mathrm{mr}}+K_{0 \mathrm{~b}} \dot{x}_{\mathrm{mr}}+\alpha_{\mathrm{b}} \dot{z}_{\mathrm{mr}}\right) \hat{v}_{\mathrm{c}} \\
& +\left(C_{0 \mathrm{~b}} \dot{x}_{\mathrm{mr}}+K_{0 \mathrm{~b}} x_{\mathrm{mr}}+\alpha_{\mathrm{b}} z_{\mathrm{mr}}\right) v_{\mathrm{a}} .
\end{aligned}
$$




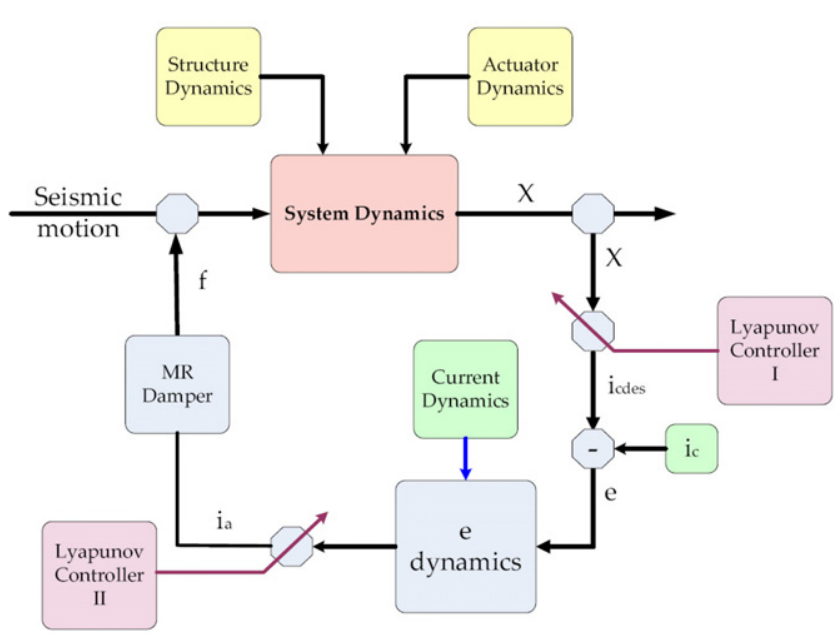

Figure 6. Schematic diagram of integral backstepping based MR damper monitoring.

The voltage supplied to the MR damper is represented by $v_{\mathrm{a}}$, whereas the voltage driving the magnetic flux, i.e., at the damper magnetic coils (also known as commanded voltage), is represented by $v_{\mathrm{c}}$. $\hat{v}_{\mathrm{c}}$ represents the measured value of the commanded voltage obtained from on-line integration using Simulink ${ }^{\circledR}$ [17]. Substituting $\dot{u}(t)$ from equation (15) into equation (13), the following simplified form of the supply voltage is obtained:

$$
\begin{aligned}
v_{\mathrm{a}}= & \left\{\dot{f}+\frac{k_{e}}{2}(u-f)-\left[\left(C_{0 \mathrm{a}} \ddot{x}_{\mathrm{mr}}+K_{0 \mathrm{a}} \dot{x}_{\mathrm{mr}}+\alpha_{\mathrm{a}} \dot{z}_{\mathrm{mr}}\right)\right.\right. \\
& -\left(C_{0 \mathrm{~b}} \dot{x}_{\mathrm{mr}}+K_{0 \mathrm{~b}} x_{\mathrm{mr}}+\alpha_{\mathrm{b}} z_{\mathrm{mr}}\right) \eta \hat{v}_{\mathrm{c}} \\
& \left.\left.+\left(C_{0 \mathrm{~b}} \ddot{x}_{\mathrm{mr}}+K_{0 \mathrm{~b}} \dot{x}_{\mathrm{mr}}+\alpha_{\mathrm{b}} \dot{z}_{\mathrm{mr}}\right) \hat{v}_{\mathrm{c}}\right]\right\} \\
& \times\left\{\left(C_{0 \mathrm{~b}} \dot{x}_{\mathrm{mr}}+K_{0 \mathrm{~b}} x_{\mathrm{mr}}+\alpha_{\mathrm{b}} z_{\mathrm{mr}}\right)\right\}^{-1} .
\end{aligned}
$$

It is to be noted that when the system dynamics at the damper location goes to zero (particularly in steady state condition) or in any situation where $x_{\mathrm{mr}}$ and $\dot{x}_{\mathrm{mr}}\left(z_{\mathrm{mr}} \rightarrow 0\right.$ as $x$, $\dot{x}_{\mathrm{mr}} \rightarrow 0$ ) simultaneously go to zero, an unstable situation may arise in the computed applied voltage. However, this is unlikely as in that case the prescribed force by the primary controller should be zero and the algorithm ends up in a $\frac{0}{0}$ position. To avoid such a numerically unstable situation, the supply voltage near the zero state condition is redefined as

$$
v_{\mathrm{a}, \text { redefined }}=\left[\begin{array}{cc}
0 & x_{\mathrm{mr}}<\mathrm{tol}_{1} \text { and } \dot{x}_{\mathrm{mr}}<\mathrm{tol}_{2} \\
v_{\mathrm{a}} & \text { otherwise }
\end{array}\right]
$$

where the values for tolerance ( $\operatorname{tol}_{1}$ and $\mathrm{tol}_{2}$ ) have to be set by the designer. Physically, when a vibration at a damper location stops the MR damper stops providing any force as it is a semiactive system. Therefore $v_{\mathrm{a}}$ has been redefined to match the physical behaviour of the damper.

Most real-world structures need multiple controllers for their vibration mitigation due to their huge masses. Therefore it becomes necessary to extend the control algorithms for systems with multiple inputs and multiple outputs (MIMO systems). In the case of multiple MR dampers the dynamic inversion algorithm can be augmented with optimization

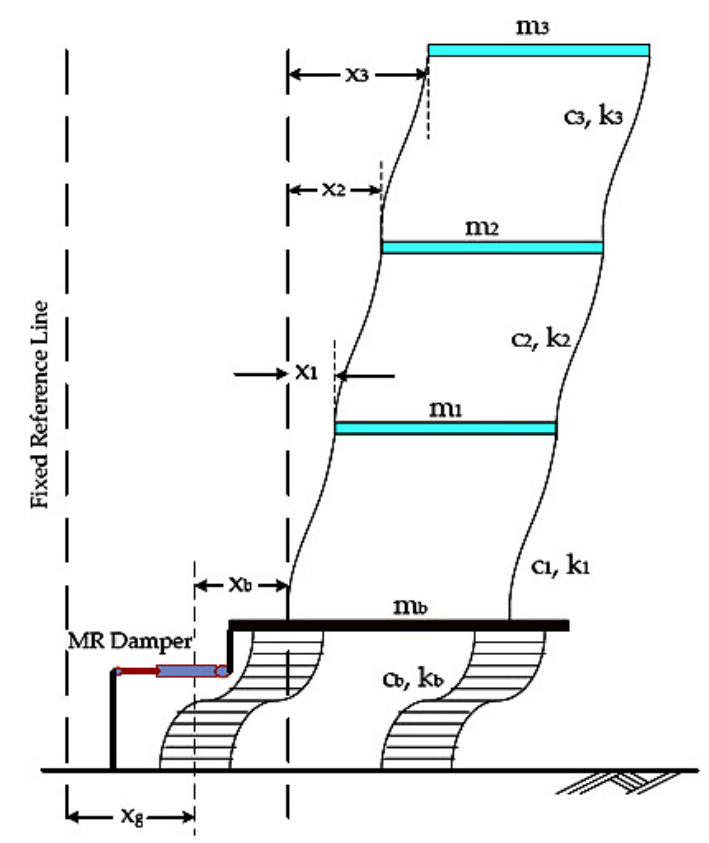

Figure 7. Schematic diagram of a hybrid base isolated building.

techniques to provide the optimal voltage to each of the dampers. An application with multiple MR dampers on a benchmark base isolated bridge is shown in [23].

\subsection{Integrator backstepping based control}

In section 3.3, the design of a model based controller to monitor MR damper voltage is detailed. Unlike other model based controllers it provides a gradual switch of damper voltage and so the actual voltage input required is provided (not switching between maximum and zero voltage). Furthermore, the DI based technique considers the input voltage dynamics of the MR damper in its algorithm development. Nevertheless it has a drawback in that one needs to design an intermediate controller like $\mathrm{H}_{2} / \mathrm{LQG}$ and then employ dynamic inversion to determine the voltage required to be supplied to the MR damper such that the control force prescribed by the intermediate controller is supplied. Another shortfall of the above controller is that it needs an estimate of the commanded voltage for its design. The main scope of this section is to design a stable semi-active controller maintaining the good features of the DI algorithms but eliminating the intermediate primary controller, and for this the integral backstepping controller proposed by Krstic et al [24] has been adopted in this study.

In recent adaptive and robust control literature, the backstepping design provides a systematic framework for the design of tracking and regulation strategies (see [24]; [25]), suitable for a large class of state feedback linearizable nonlinear systems. Integrator backstepping is used to systematically design controllers for systems with known nonlinearities. The approach can be extended to handle systems with unknown parameters, via adaptive backstepping. However, adaptive backstepping design for nonlinear control may dramatically increase the complexity of the controller. 

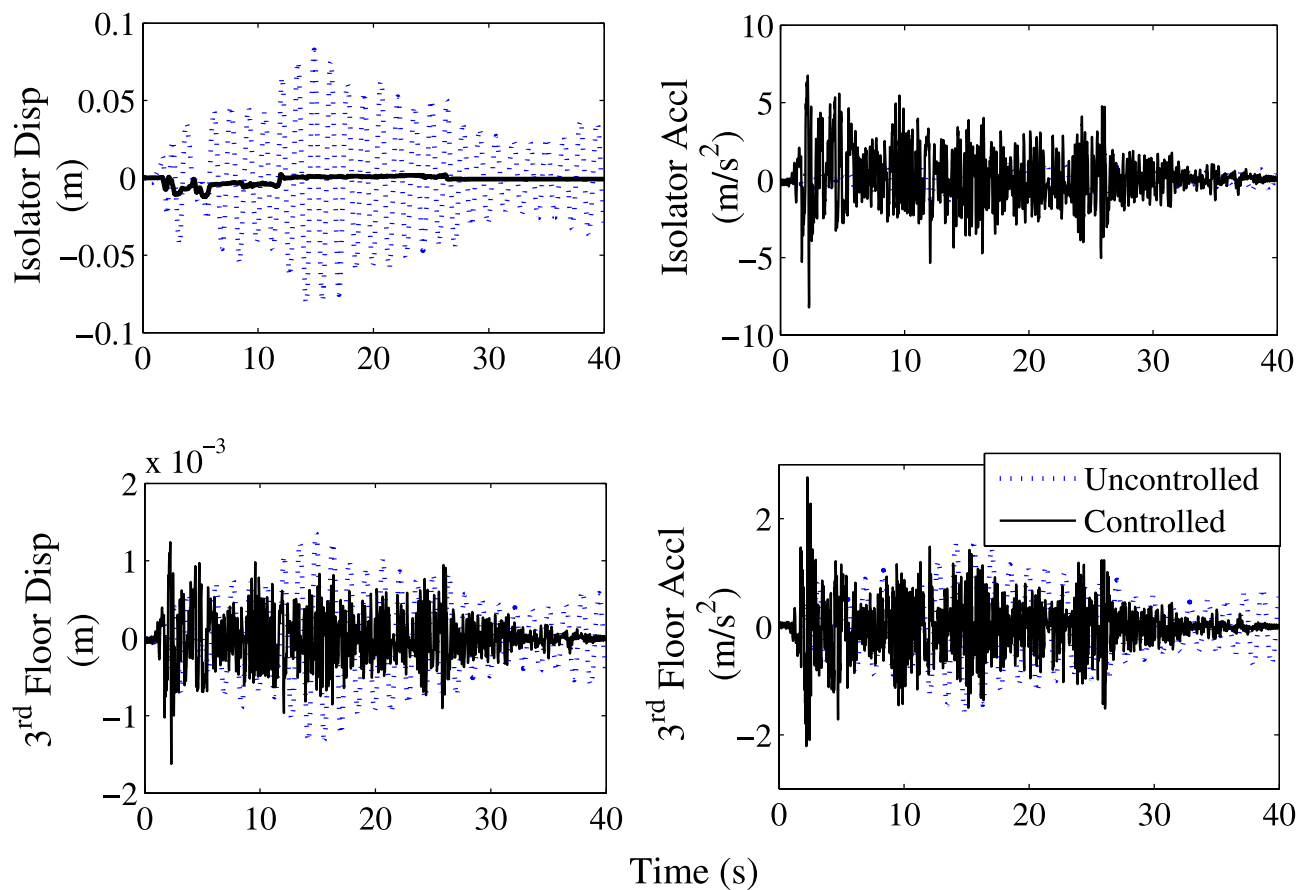

Figure 8. Base isolator and third-floor displacement and acceleration responses under El Centro ( $X$ - seismic fault normal component) (uncontrolled and DI based control).

In the present paper, integrator backstepping is applied to deduce the voltage required by the MR damper to minimize the structural responses.

The development of the algorithm is shown in the schematic diagram, figure 6 . It is also a two-stage controller, where in the first stage a Lyapunov controller is developed to stabilize the dynamics of the structural system. Thereafter, considering the MR damper input voltage dynamics, a second Lyapunov based controller is developed to stabilize the full system, considering the structural system and the MR damper.

The integral backstepping based semi-active MR damper voltage monitoring is developed for a SDOF system. The base isolated building considered for this study is in effect an SDOF system due to the base isolation [26].

\subsection{System model}

An SDOF model is considered with an MR damper connected to it. The linear dynamics of SDOF systems with an MR damper is given by

$$
m \ddot{x}+c \dot{x}+k x+u(t)=f(t)
$$

where $m, c$, and $k$ are the mass, damping, and stiffness of the SDOF system and $(\cdot)$ denotes the derivative w.r.t. time $(t)$. $u(t)$ is the MR damper control force and $f(t)$ is the external excitation force. $u(t)$ is added as the system restoring force as the MR damper acts as a passive device in the absence of driver voltage.

Substituting $u(t)=c_{0} \dot{x}_{\mathrm{mr}}+k_{0} x_{\mathrm{mr}}+\alpha z_{\mathrm{mr}}$ in equation (18) and then rewriting the closed loop system dynamics considering the MR damper dynamics (and neglecting the
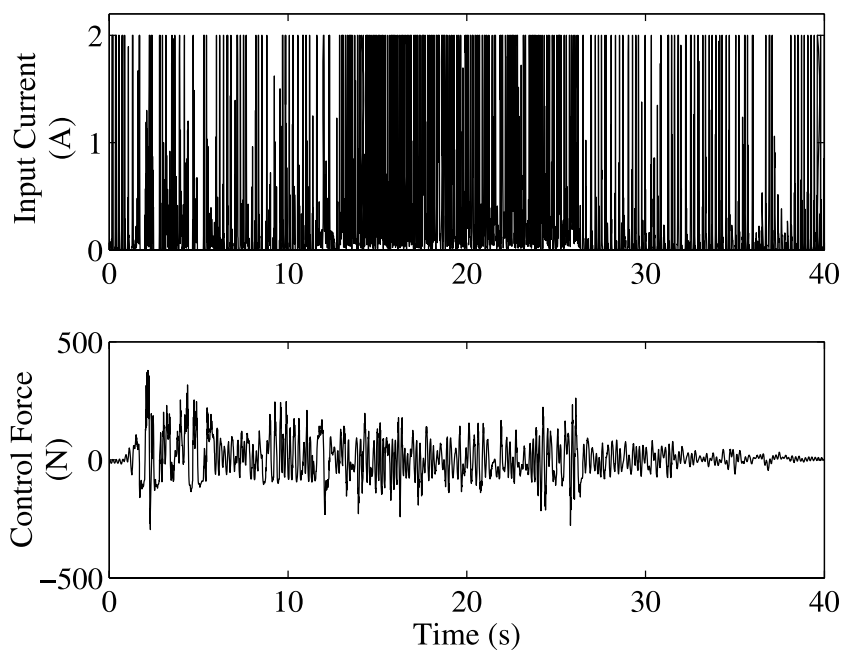

Figure 9. Input voltage and damper force under El Centro (DI based control).

external forcing term) in state space form, one gets

$\dot{x}_{1}=x_{2}$;

$\dot{x}_{2}=-\frac{1}{m}\left\{\left(k+k_{0 \mathrm{a}}\right) x_{1}+\left(c+c_{0 \mathrm{a}}\right) x_{2}+\alpha_{\mathrm{a}} x_{3}\right\}$

$-\frac{1}{m}\left\{k_{0 \mathrm{~b}} x_{1}+c_{0 \mathrm{~b}} x_{2}+\alpha_{\mathrm{b}} x_{3}\right\} v_{\mathrm{c}} ;$

$\dot{x}_{3}=-\gamma\left|\dot{x_{2}}\right| x_{3}\left|x_{3}\right|^{n-1}-\beta \dot{x_{2}}\left|x_{3}\right|^{n}+A \dot{x_{2}} ;$

$\dot{v}_{\mathrm{c}}=-\eta\left(v_{\mathrm{c}}-v_{\mathrm{a}}\right)$.

In equation (19), the evolutionary variable $z_{\mathrm{mr}}$ (see equation (1)) is replaced with $x_{3}$. Since an SDOF system is 

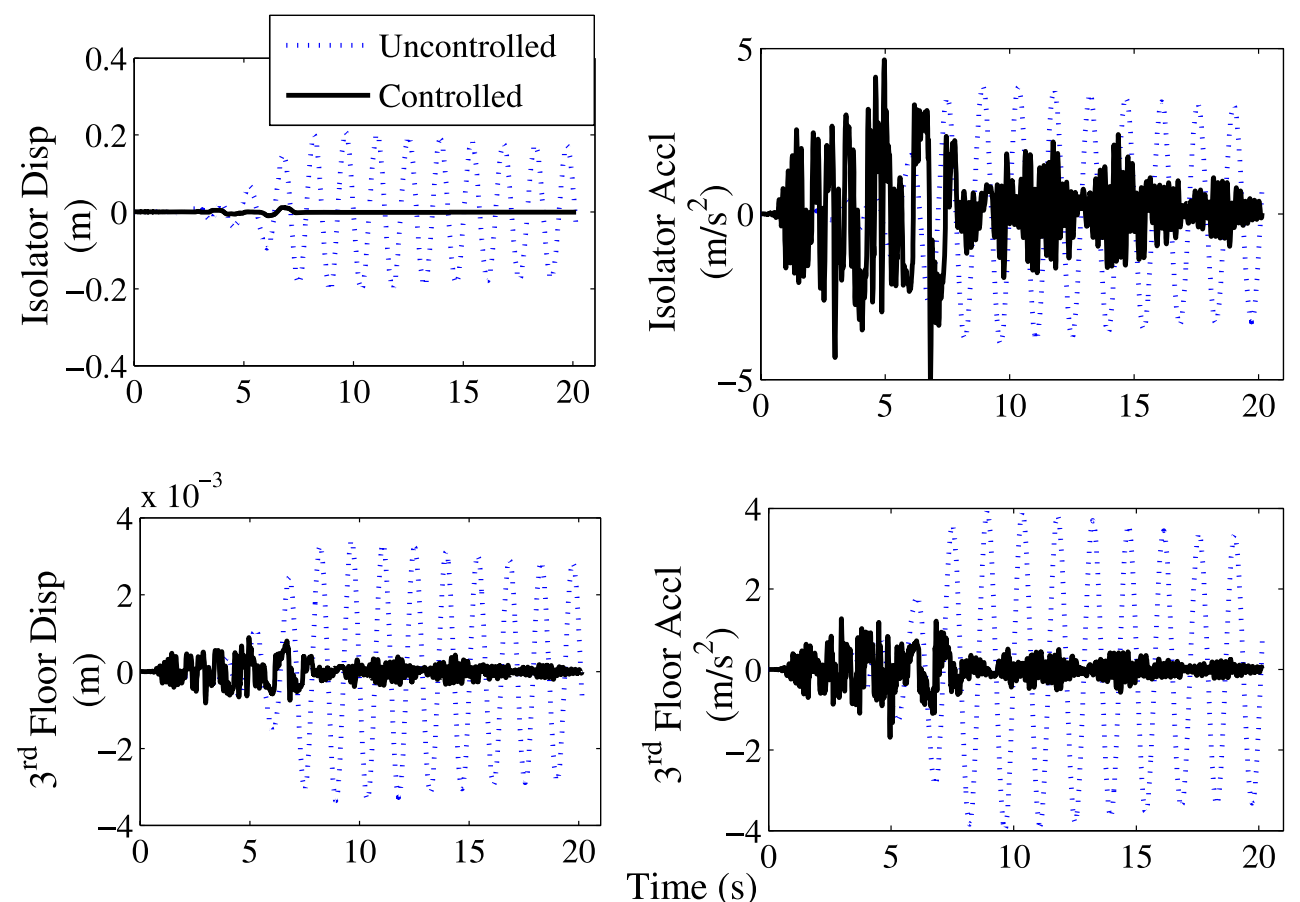

Figure 10. Base isolator and third-floor displacement and acceleration responses under North Palm Spring ( $X$ —seismic fault normal component) (uncontrolled and DI based control).

considered, $x_{\mathrm{mr}}=x=x_{1}$ and $\dot{x}_{\mathrm{mr}}=\dot{x}=x_{2}$. The variable $z_{\mathrm{mr}}$ is responsible for the hysteretic behaviour of the MR damper and it evolves with time. Therefore it is a hidden variable and is considered as an additional state variable.

Equation (19) can be rewritten in the following standard form:

$$
\begin{gathered}
\dot{X}=F_{1}(t, X)+G_{1}(t, X) v_{\mathrm{c}} \\
\dot{v}_{\mathrm{c}}=F_{2}\left(t, X, i_{\mathrm{c}}\right)+G_{2}\left(t, X, i_{\mathrm{c}}\right) v_{\mathrm{a}}
\end{gathered}
$$

where $X, F_{1}, G_{1}, F_{2}$ and $G_{2}$ are given in equation (21).

$X=\left[x_{1}, x_{2}, x_{3}\right]^{\mathrm{T}}$;

$F_{1}=\left[x_{2}-\frac{1}{m}\left\{\left(k+k_{0 \mathrm{a}}\right) x_{1}+\left(c+c_{0 \mathrm{a}}\right) x_{2}+\alpha_{\mathrm{a}} x_{3}\right\}\right.$

$\left.-\gamma\left|\dot{x_{2}}\right| x_{3}\left|x_{3}\right|^{n-1}-\beta \dot{x_{2}}\left|x_{3}\right|^{n}+A \dot{x_{2}}\right]$;

$G_{1}=\left[0,-\frac{1}{m}\left\{k_{0 \mathrm{~b}} x_{1}+c_{0 \mathrm{~b}} x_{2}+\alpha_{\mathrm{b}} x_{3}\right\}, 0\right]^{\mathrm{T}} ;$

$F_{2}=-\eta i_{\mathrm{c}} ; \quad G_{2}=\eta$

where ()$^{\mathrm{T}}$ represents transpose operation.

\subsection{Backstepping controller design}

Equations (20) are a second-order strict feedback form of the system given by equations (19). We define a dummy variable $v_{\text {dum }}$ such that it satisfies the following relation:

$$
v_{\mathrm{a}}=\frac{1}{G_{2}\left(t, X, v_{\mathrm{c}}\right)}\left(v_{\mathrm{dum}}-F_{2}\left(t, X, v_{\mathrm{c}}\right)\right) .
$$

The dummy variable $\left(v_{\text {dum }}\right)$ is defined to convert the second-order strict feedback system to a simplified form amenable for integrator backstepping application. Combining equations (20) and (22), we reduce the strict feedback system to an integrator backstepping form:

$$
\begin{gathered}
\dot{X}=F_{1}(t, X)+G_{1}(t, X) v_{\mathrm{c}} \\
\dot{v}_{\mathrm{c}}=v_{\mathrm{dum}} .
\end{gathered}
$$

The design objective is $X(t) \rightarrow 0$ as $t \rightarrow \infty$. The control law can be synthesized in two steps. We regard the commanded voltage, $v_{\mathrm{c}}$, to the damper as the real voltage driver, first. By choosing the Lyapunov candidate function of the system as $V_{1}=1 / 2\left(k x_{1}^{2}+m x_{2}^{2}+q x_{3}^{2}\right)$, we get

$$
\begin{aligned}
\dot{V}_{1}= & {\left[-\left\{\left(c+c_{0 \mathrm{a}}\right) x_{2}^{2}+\gamma q\left|x_{2} x_{3}\right| x_{3}^{2}\right\}\right.} \\
& -\left\{k_{0 \mathrm{a}} x_{1} x_{2}+\left(\alpha_{\mathrm{a}}-A q\right) x_{2} x_{3}+q \beta x_{2} x_{3}^{3}\right. \\
& \left.\left.+\left(k_{0 \mathrm{~b}} x_{1} x_{2}+c_{0 \mathrm{~b}} x_{2}^{2}+\alpha_{\mathrm{b}} x_{2} x_{3}\right) v_{\mathrm{c}}\right\}\right] .
\end{aligned}
$$

The Lyapunov time-derivative $\dot{V}_{1}$ should be made negative-definite to get a stable closed loop system. The first term in $\dot{V}_{1}$, i.e., $\left\{\left(c+c_{0 \mathrm{a}}\right) x_{2}^{2}+\gamma q\left|x_{2} x_{3}\right| x_{3}^{2}\right\}$, is free of the voltage variable $v_{\mathrm{c}}$ and is negative-definite $\left(\forall x_{1}, x_{2}, x_{3}\right) . q$ is a positive constant given by $\frac{\alpha_{a}}{A}$. Out of many solutions, we select the designed commanded voltage $v_{\mathrm{c}_{\mathrm{des}}}$ to be

$$
v_{\mathrm{c}_{\mathrm{des}}}=\frac{k_{\mathrm{d}} x_{1}^{2}-K_{0 \mathrm{a}} x_{1} x_{2}-q \beta x_{2} x_{3}^{3}}{k_{0 \mathrm{~b}} x_{1} x_{2}+c_{0 \mathrm{~b}} x_{2}^{2}+\alpha_{\mathrm{b}} x_{2} x_{3}},
$$

where $k_{\mathrm{d}} \geqslant 0$ is a positive constant to be decided by the designer (as this simple form makes $\dot{V}_{1}<0 \forall x_{1}, x_{2}, x_{3} \neq 0$ ). In the present analysis, $k_{\mathrm{d}}=1$ is considered, which makes $\dot{V}_{1}=-\left\{\left(c+c_{0 \mathrm{a}}\right) x_{2}^{2}+\gamma q\left|x_{2} x_{3}\right| x_{3}^{2}+k_{\mathrm{d}} x_{1}^{2}\right\} \leqslant 0 \forall X \neq 0$ 
in equation (24). There can be a numerical stability problem when all $x_{1} \rightarrow 0, x_{2} \rightarrow 0$ and $x_{3} \rightarrow 0$ simultaneously. Therefore, a tolerance is set for all the state variables, below which the damper input voltage is kept at zero.

Nevertheless, $v_{\mathrm{c}}$ is a state variable, and perfect tracking to $v_{\mathrm{c}_{\mathrm{des}}}$ is desired and hardly achieved in reality. Therefore, an error variable $e$ (given in equation (26)) as the target error of the designed variable is defined.

$$
e=v_{\mathrm{c}}-v_{\mathrm{c}_{\mathrm{des}}} .
$$

The error dynamics is given by

$$
\begin{aligned}
\dot{e} & =\dot{v}_{\mathrm{c}}-\dot{v}_{\mathrm{c}_{\mathrm{des}}} \\
& =v_{\mathrm{dum}}-v_{\mathrm{c}_{\mathrm{des}, X}} \dot{X}
\end{aligned}
$$

where $v_{\mathrm{c}_{\text {des }, X}}$ is the derivative of $v_{\mathrm{c}_{\text {des }}}$ w.r.t. state $X$.

Choosing a second Lyapunov function as $V_{2}=V_{1}+\frac{1}{2} e^{2}$ and the voltage variable $v_{\text {dum }}$ as given in equation (28), it can be shown that the system defined in equation (23) becomes asymptotically stable (see $[22,24])$.

$$
\begin{aligned}
v_{\text {dum }} & =v_{\mathrm{c}_{\text {des }, X}}\left[F_{1}(t, X)+G_{1}(t, X) v_{\mathrm{c}}\right]-V_{1, X} \cdot G_{1}(t, X) \\
& -K\left(v_{\mathrm{c}}-v_{\mathrm{c}_{\mathrm{des}}}\right)
\end{aligned}
$$

with $F_{1}$ and $G_{1}$ defined in equation (21); $K>0$ is any constant to be decided by the designer. For our analysis $K=1$ is considered. The voltage applied to the MR damper can be obtained by substituting equation (28) into equation (22).

\section{Base isolated building simulation}

The aftermaths of the 1994 Northridge and 1995 Kobe earthquakes have resulted in a growing interest among structural engineers to evolve systems to protect structures from near-source ground motions. This is because a base isolation system [26] incorporating rubber bearings alone cannot by itself provide sufficient damping to the structure, and as a consequence the structure experiences large displacements at the base under pulse type near-field seismic motions. Such excessive displacement can result in a roll-off of the superstructure from the supporting structure or collision with nearby structures, resulting in severe structural and equipment damage.

For the present simulation study a three-storey base isolated building is considered. A single MR damper is assumed to be connected at the base of the building, as shown in figure 7. Base isolated buildings are designed such that the superstructure remains elastic. Hence, the superstructure is modelled as a three-dimensional linear elastic shear building. The equations of motion for the elastic superstructure are expressed in the following form:

$$
M_{\mathrm{a}} \ddot{U}+C_{\mathrm{a}} \dot{U}+K_{\mathrm{a}} U=-M_{\mathrm{a}} R\left(\ddot{U}_{\mathrm{g}}+\ddot{U}_{\mathrm{b}}\right),
$$

in which $M$ is the superstructure mass matrix, $C$ and $K$ are the superstructure damping and stiffness matrices, respectively, in the fixed-base case, and $R$ is the matrix of earthquake influence coefficients. Furthermore, $\ddot{U}, \dot{U}$, and $U$ represent the floor acceleration, velocity, and displacement vectors relative to the base, respectively, $\ddot{U}_{\mathrm{b}}$ is the vector of base accelerations (at
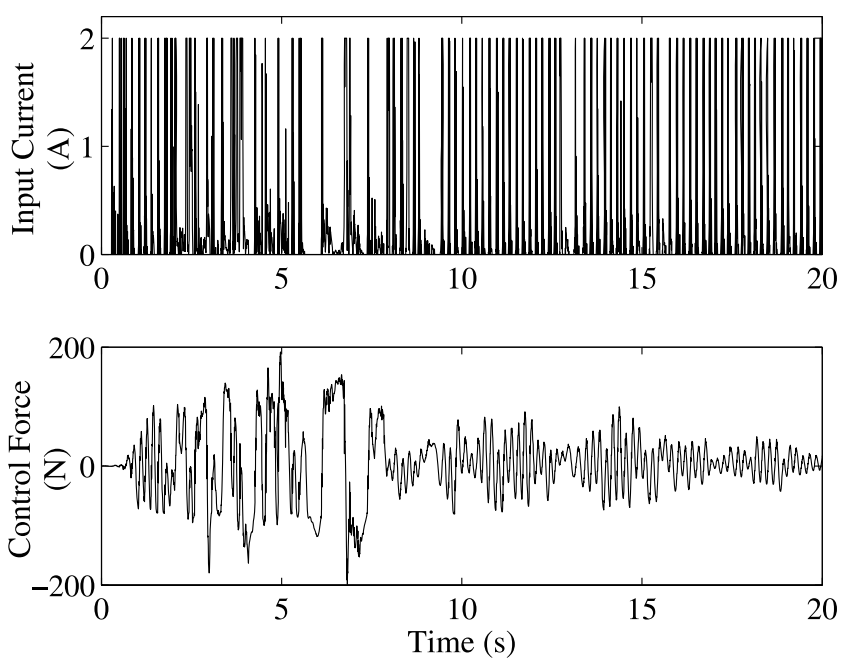

Figure 11. Input voltage and damper force under North Palm Spring (DI based control).

isolation level) relative to the ground, and $\ddot{U}_{\mathrm{g}}$ is the vector of ground accelerations. The equations of motion for the base are as follows:

$$
\begin{aligned}
& R^{\mathrm{T}} M_{\mathrm{a}}\left[\ddot{U}+R\left(\ddot{U}_{\mathrm{g}}+\ddot{u}_{\mathrm{b}}\right)\right]+m_{\mathrm{b}}\left(\ddot{U}_{\mathrm{g}}+\ddot{u}_{\mathrm{b}}\right)+c_{\mathrm{b}} \dot{u}_{\mathrm{b}} \\
& \quad+k_{\mathrm{b}} u_{\mathrm{b}}+f_{\mathrm{c}}=0 .
\end{aligned}
$$

The mass $\left(M_{\mathrm{a}}\right)$, damping $\left(C_{\mathrm{a}}\right)$, and stiffness $\left(K_{\mathrm{a}}\right)$ matrices considered for simulation are given as

$$
\begin{gathered}
M_{\mathrm{a}}=\left[\begin{array}{ccc}
62.76 & 0 & 0 \\
0 & 64.20 & 0 \\
0 & 0 & 59.40
\end{array}\right] \mathrm{kg} ; \\
C_{\mathrm{a}}=\left[\begin{array}{ccc}
522.75 & -222.75 & 0 \\
-222.75 & 232.75 & -10.00 \\
0 & -10.00 & 10.00
\end{array}\right] \mathrm{N} \mathrm{s} \mathrm{m}^{-1} \\
K_{\mathrm{a}}=\left[\begin{array}{ccc}
1.0394 & -0.7338 & 0 \\
-0.7338 & 1.4931 & -0.7593 \\
0 & -0.7593 & 0.7593
\end{array}\right] \times 10^{6} \mathrm{~N} \mathrm{~m}^{-1} .
\end{gathered}
$$

The mass of the base is considered to be $m_{\mathrm{b}}=38 \mathrm{~kg}$. The stiffness $\left(k_{\mathrm{b}}\right)$ at the base is assumed to be $4.32 \mathrm{kN} \mathrm{m}^{-1}$ and a $1 \%$ coefficient of damping is assumed at the base. The mass, stiffness, and damping matrices are considered such that the isolated building has a maximum $0.2 \mathrm{~m}$ isolator displacement under the seismic excitations considered.

Simulations are carried out for a dynamic inversion and an integrator backstepping controller. The performance of the proposed MR damper voltage monitoring techniques is shown for a set of seismic motions. A comparison is reported with a GA-FLC controller and an LQR-clipped optimal control algorithm. In the analysis reported in section 4.1, the uncontrolled state of the structure is assumed to be the building with only the base isolator (without an MR damper, i.e., simple base isolation), and the controlled state is considered to be the building with a base isolator and an MR damper. This is to show the benefits of a supplemental damping device attached to the isolator in comparison to the simple isolation system. 

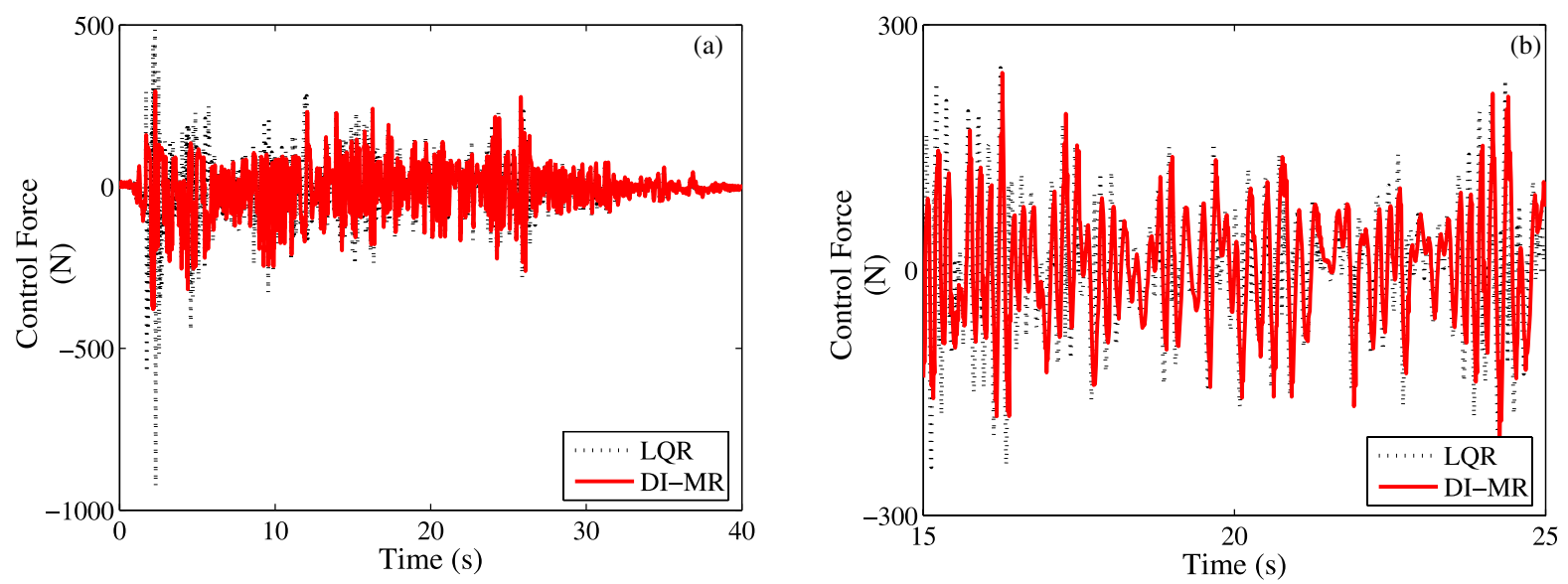

Figure 12. Tracking performance of the MR damper with DI (El Centro ( $X$-seismic fault normal component)). (a) Tracking performance of the MR damper with DI. (b) Tracking performance of the MR damper with DI (enlarged).
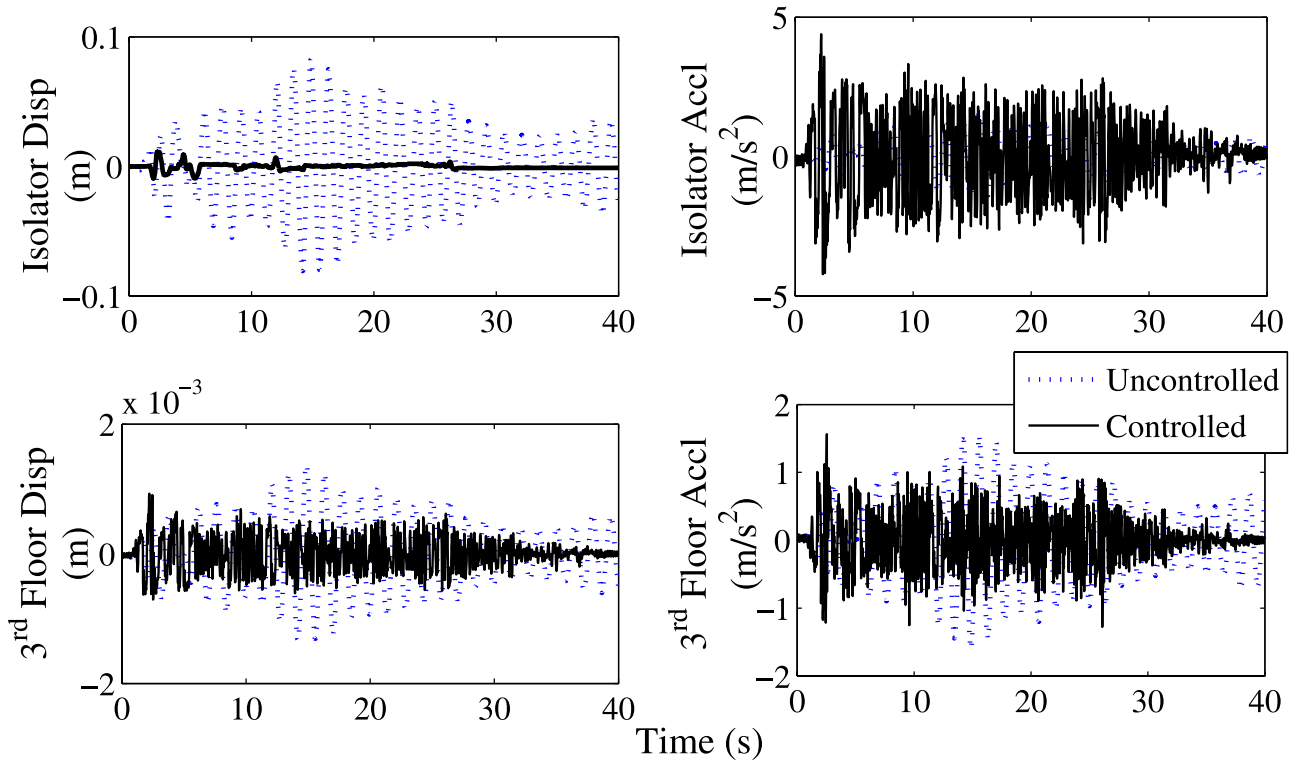

Figure 13. Base isolator and third-floor displacement and acceleration responses under El Centro ( $X$ —seismic fault normal component) (uncontrolled and backstepping control).

Table 2. Performance indices for comparative study of control strategies.

\begin{tabular}{|c|c|c|}
\hline $\begin{array}{l}\text { Peak base displacement } \\
J_{1}=\frac{t_{\max }\left|x_{\mathrm{b}}(t)\right|}{t_{\max } \mid x_{\mathrm{b}} \text { unc }(t) \mid}\end{array}$ & $\begin{array}{l}\text { Peak floor displacement } \\
J_{2}=\frac{t_{\max }\left|x_{n} \mathrm{c}(t)\right|}{t_{\max } \mid x_{n} \text { unc }(t) \mid}\end{array}$ & $\begin{array}{l}\text { Peak base velocity } \\
J_{3}=\frac{t_{\max }\left|\dot{\mathrm{x}}_{\mathrm{c}}(t)\right|}{t_{\max }\left|\dot{x}_{\mathrm{b} \text { unc }}(t)\right|}\end{array}$ \\
\hline $\begin{array}{l}\text { Peak floor } \mathrm{v} \\
J_{4}=\frac{t_{\max } \mid \dot{x}_{n}}{t_{\max } \mid \dot{x}_{n}}\end{array}$ & $J_{5}=\frac{t_{\max } \mid}{t_{\max } \mid \ddot{x}}$ & $\begin{array}{l}\text { Peak floc } \\
J_{6}=\frac{t_{\mathrm{ma}}}{t_{\max }}\end{array}$ \\
\hline $\begin{array}{l}\text { Peak control force } \\
J_{7}=t_{\max }|u(t)|\end{array}$ & $\begin{array}{l}\text { Peak voltage input } \\
J_{8}=t_{\max }\left|i_{\mathrm{a}}(t)\right|\end{array}$ & - \\
\hline 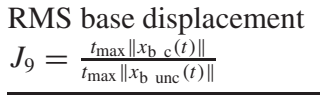 & $\begin{array}{l}\text { RMS floor displacement } \\
J_{10}=\frac{t_{\max }\left\|x_{n}(t)\right\|}{t_{\max } \| x_{n} \text { unc }(t) \|}\end{array}$ & $\begin{array}{l}\text { RMS base velocity } \\
J_{11}=\frac{t_{\max }\left\|\dot{x}_{\mathrm{b}}(t)\right\|}{t_{\max }\left\|\dot{\mathrm{x}}_{\mathrm{b} \text { unc }}(t)\right\|}\end{array}$ \\
\hline $\begin{array}{l}\text { RMS floor velocity } \\
J_{12}=\frac{t_{\max }\left\|\dot{x}_{n \mathrm{c}}(t)\right\|}{t_{\max }\left\|\dot{x}_{n \text { unc }}(t)\right\|}\end{array}$ & $\begin{array}{l}\text { RMS base accelerati } \\
J_{13}=\frac{t_{\max }\left\|\ddot{x}_{\mathrm{b}}(t)\right\|}{t_{\max }\left\|\ddot{x}_{\mathrm{b} \text { unc }}(t)\right\|}\end{array}$ & $\begin{array}{l}\text { RMS floor accelerat } \\
J_{14}=\frac{t_{\max }\left\|\ddot{x}_{\mathrm{c}}(t)\right\|}{t_{\max }\left\|\ddot{x}_{n \text { unc }}(t)\right\|}\end{array}$ \\
\hline
\end{tabular}

\subsection{Seismic analysis: dynamic inversion controller}

Figure 8 shows the time history of the uncontrolled and controlled system responses (displacement and acceleration) of the base isolator and at the third floor under El Centro ground motion. The uncontrolled (simple base isolation) and controlled (hybrid isolation) displacement and acceleration responses are shown together for better comparison. The 
peak displacement response of the isolator in the simple isolation condition is found to be $0.0827 \mathrm{~m}$, which is reduced to $0.0123 \mathrm{~m}$ by the DI monitored MR damper. The third floor shows a slight increase in the displacement response from $0.0014 \mathrm{~m}$ in the uncontrolled condition to $0.0016 \mathrm{~m}$ in the MR damper controlled case. The acceleration response at the isolator and at the superstructure is increased due to the implementation of the MR damper, which is very usual for hybrid base isolated structures. Since the MR damper decreases the isolator displacement, the superstructure responses increase. The base acceleration of $1.5631 \mathrm{~m} \mathrm{~s}^{-2}$ in the uncontrolled case is increased to $8.2246 \mathrm{~m} \mathrm{~s}^{-2}$ in the MR controlled case. A drop in the isolator velocity from $0.3847 \mathrm{~m} \mathrm{~s}^{-1}$ in the uncontrolled case to $0.0690 \mathrm{~m} \mathrm{~s}^{-1}$ in the controlled case is also observed.

The control force provided by the MR damper and the corresponding input voltage to the MR damper are shown in figure 9. It is clear from the input voltage time history that the voltage supplied reaches the maximum but it also considers current (voltage) values in between zero and maximum $2 \mathrm{~A}$ (equivalent to $5 \mathrm{~V}$ voltage).

Similar to figure 8, the responses due to the North Palm Spring seismic ground motion are shown in figure 10. A maximum isolator displacement of $0.2077 \mathrm{~m}$ is reduced to $0.0113 \mathrm{~m}$. Unlike the case of El Centro seismic ground motion, a better performance of MR damper is observed in the North Palm Spring earthquake. The isolator acceleration and the superstructure displacement responses are reduced using the MR damper. Only the superstructure acceleration response has increased over that of the uncontrolled case.

The control force provided by the MR damper and the corresponding input voltage to the MR damper in the North Palm Spring seismic motion are shown in figure 11. Similar to the El Centro case, the DI based algorithm provides voltage values in between the zero and maximum voltage range.

The tracking performance of the DI algorithm for the El Centro earthquake case is shown in figure 12. Figure 12 contains both the force prescribed by the LQR algorithm and the force provided by the MR damper using input from the DI based tracking algorithm.

\subsection{Seismic analysis: integrator backstepping controller}

Base isolated structures behaves as a rigid mass over the base under seismic ground motion [26]. Therefore SDOF models provide a good approximation to these systems for quick calculation under ground motion [26]. The integrator backstepping based algorithm is developed assuming an SDOF system with mass equal to the total mass of the threestorey base isolated building and stiffness equal to that of the base stiffness. The tolerance for the simulation studies with backstepping is set to tol $_{1}=1 \times 10^{-5} \mathrm{~m}$ for isolator displacement and tol $2=1 \times 10^{-5} \mathrm{~m} \mathrm{~s}^{-1}$ for isolator velocity.

Figure 13 shows the time histories of the uncontrolled (simple isolation) and controlled system (hybrid isolation) responses of base isolator and at the third floor under El Centro ground motion. The uncontrolled and controlled displacement and acceleration responses are shown together
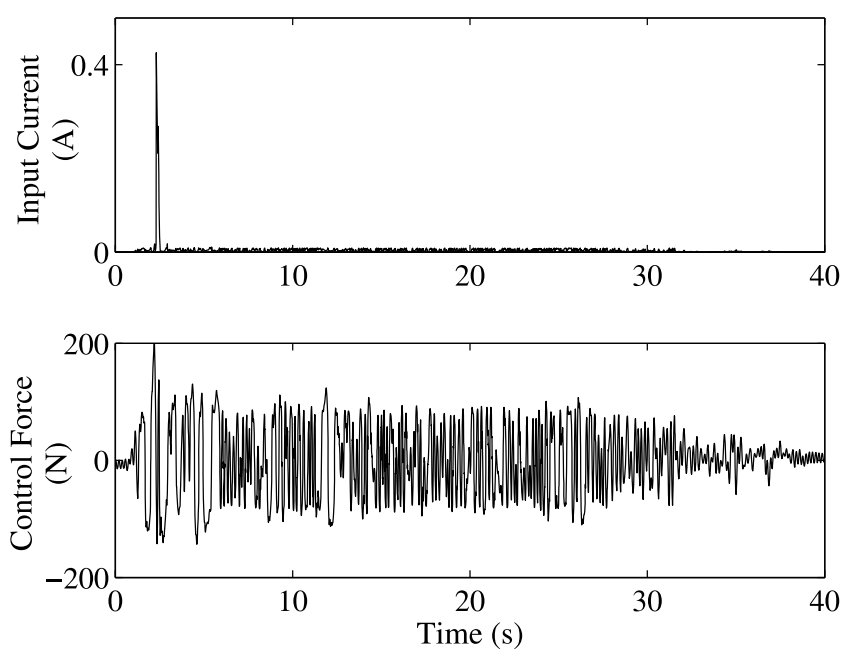

Figure 14. Input voltage and damper force under El Centro ( $X$-seismic fault normal component) (backstepping control).

for better comparison. The peak displacement response of the isolator is found to be $0.0827 \mathrm{~m}$, which has been minimized to $0.0112 \mathrm{~m}$ by the integral backstepping monitored MR damper. The isolator acceleration is observed to increase from 1.5631 to $4.3883 \mathrm{~m} \mathrm{~s}^{-2}$ with backstepping based control, which is a smaller increase in comparison to that obtained through DI based control.

The third-floor displacement is also reduced from $0.0014 \mathrm{~m}$ in the uncontrolled (simple isolation) condition to $0.0009 \mathrm{~m}$ in the MR damper controlled (hybrid isolation) case, but at the same time the acceleration has increased. The control force provided by the MR damper and the corresponding input voltage to the MR damper are shown in figure 14. It is clear from the input voltage time history shown in figure 14 that only a small amount of voltage input is needed to mitigate the vibration caused by the El Centro ground motion. Therefore, switching the input voltage from zero to maximum based on system responses decreases the system performance under seismic motions.

Similar to figure 13, the responses under North Palm Spring seismic ground motion are shown in figure 15 . The performance of the backstepping based controller is quite evident from figure 15 itself. The maximum isolator displacement of $0.2077 \mathrm{~m}$ is reduced to $0.0157 \mathrm{~m}$. The isolator acceleration and the superstructure displacement responses are also reduced using backstepping based MR damper control. Only the superstructure acceleration response is increased over that of the uncontrolled case.

The current input to the MR damper for the above performance is shown in figure 16. Figure 16 also shows the force provided by the MR damper to the system. It is seen that the MR damper maximum current ( $2 \mathrm{~A}$ ) input is not required.

\section{Comparative analysis of control strategies}

This section reports a comparative analysis of proposed control strategies with optimal FLC and clipped optimal (CO) strategies. Eight sets of seismic ground motion data are considered for the study (shown in table 3 ). For the comparison 

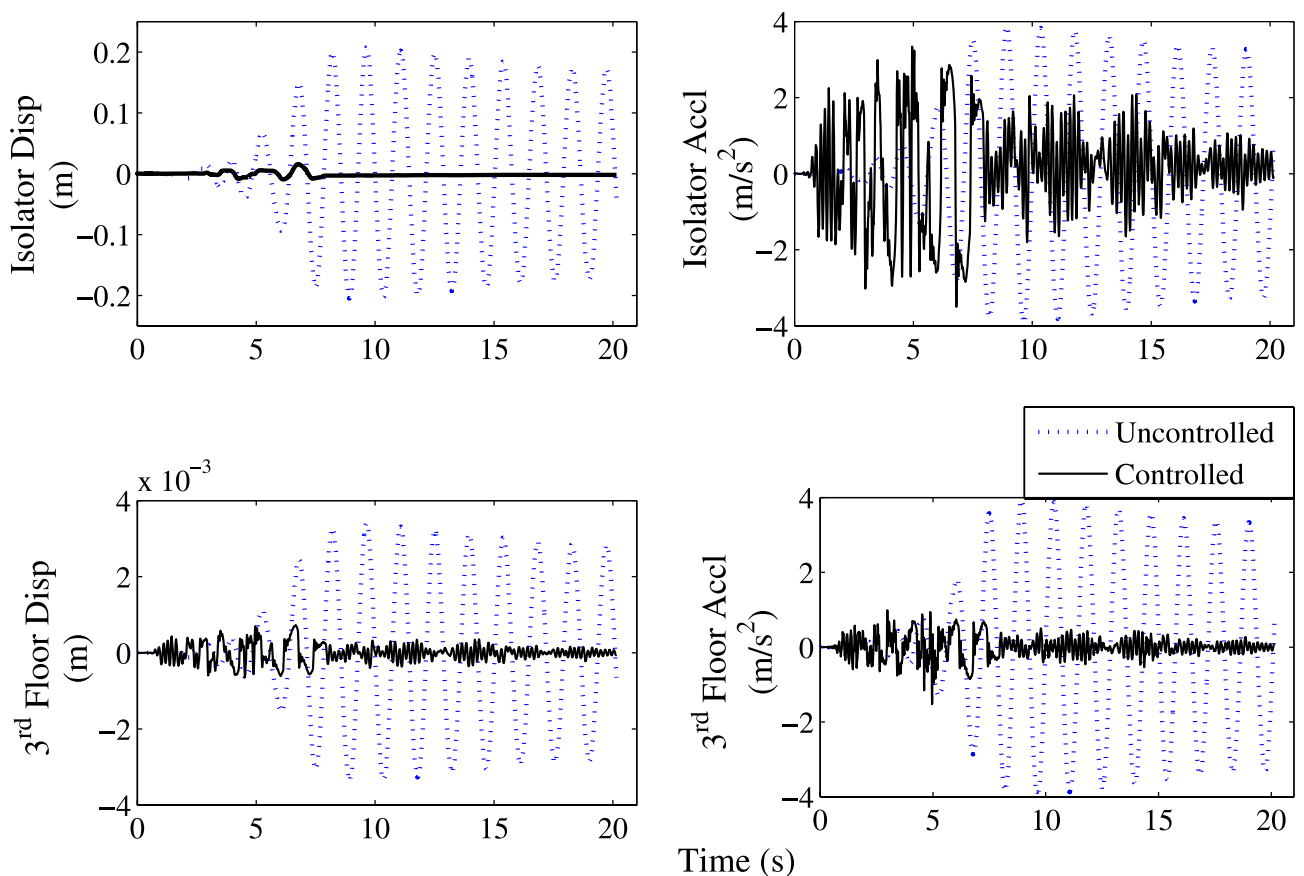

Figure 15. Base isolator and third-floor displacement and acceleration responses under North Palm Spring ( $X$ —seismic fault normal component) (uncontrolled and backstepping control).
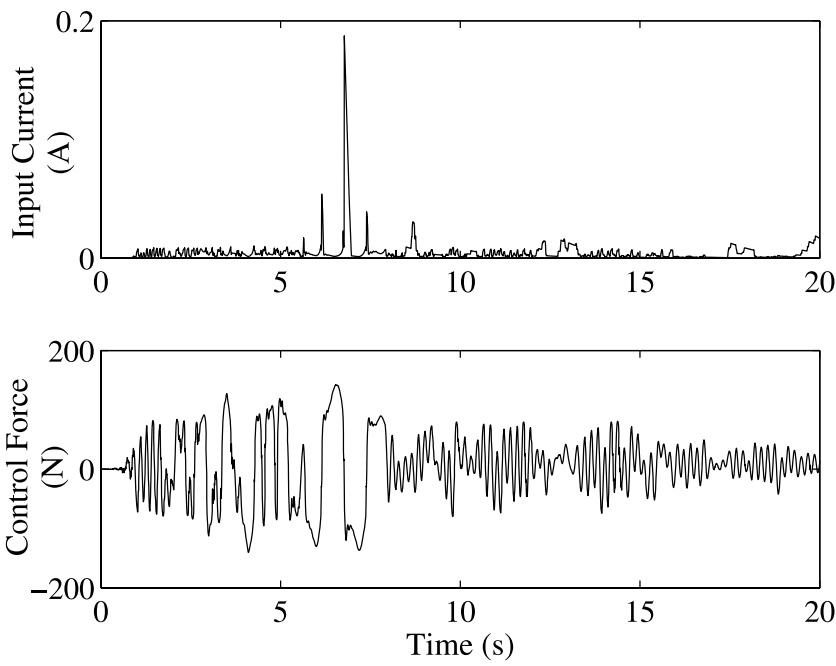

Figure 16. Input voltage and damper force under North Palm Spring ( $X$-seismic fault normal component) (backstepping control).

of different control schemes a set of performance indices has been considered and is given in table 2 .

In table $2,|\cdot|$ denotes the absolute value and $\|\cdot\|$ denotes the $\mathrm{L}_{2}$ norm. The subscripts ${ }_{\mathrm{c}}$ and $\mathrm{unc}_{\text {denote the controlled }}$ and uncontrolled responses, respectively. The maximum of the responses is considered over time $\left(t_{\max }\right)$. The floor responses are computed as the maximum over the floor, where $n$ denotes the $n$th floor $(n=1-3)$.

The results obtained from numerical study of various control strategies are tabulated in tables 3 and 4 . The normalized maximum responses are shown in table 3 , while the response norms are shown in table 4.
All four controllers minimize the base isolator displacement response $\left(J_{1}\right)$ for all eight seismic motions. The base displacement minimizes to a range of $1 \%-5 \%$ of its value for the no damper case (simple isolation system). This shows the performance of the hybrid isolation technique in reducing isolator displacements. LQR-CO is observed to minimize the base displacement more than any other controller.

The decrease in $J_{1}$ has shown an increase in superstructure displacement $\left(J_{2}\right)$ for most of the seismic excitations. This is observed particularly for the LQR-CO and optimal FLC cases. Integrator backstepping based MR damper monitoring provides a reduction in the floor displacement responses for all seismic motion except for Coalinga seismic motion data, where it provides less increase than other controllers. Therefore, the superstructure performance is seen to be better in the backstepping based control scheme. The backstepping based control scheme has also outperformed the other controllers in performances $J_{3}$ and $J_{4}$.

It is to be noted that the decrease in base isolator displacement response increases the isolator acceleration response. From the performance index $\left(J_{5}\right)$, it is observed that the isolator acceleration is increased by all control schemes under all seismic motions, excepts under the Chichi earthquake with the backstepping control scheme, where a decrease of about $23 \%$ is seen from that of the simple base isolation strategy. The maximum increase in acceleration is seen for the clipped optimal strategy. This is because the $\mathrm{CO}$ case has shown least values for the base displacement. The minimum increase is shown by integral backstepping base MR damper control. The superstructure peak acceleration response is seen to decrease with all control schemes under almost all seismic motions excepts under Coalinga and El Centro seismic motions, where an increase in storey acceleration is seen. 
Table 3. Peak responses of hybrid base isolated building for $X$-direction (seismic fault parallel component) seismic motion.

\begin{tabular}{|c|c|c|c|c|c|c|c|c|c|}
\hline \multirow[b]{2}{*}{ PI } & \multirow[b]{2}{*}{ Control } & \multicolumn{8}{|c|}{ Earthquake records } \\
\hline & & Big Bear & Capemend & Chichi & Coalinga & El Centro & Loma prieta & North Palm Spring & Kobe \\
\hline \multirow[t]{4}{*}{$\overline{J_{1}}$} & DI & 0.057 & 0.027 & 0.043 & 0.150 & 0.148 & 0.036 & 0.055 & 0.022 \\
\hline & IB & 0.050 & 0.062 & 0.044 & 0.299 & 0.136 & 0.033 & 0.076 & 0.023 \\
\hline & $\mathrm{CO}$ & 0.008 & 0.032 & 0.006 & 0.236 & 0.027 & 0.002 & 0.007 & 0.003 \\
\hline & GA-FLC & 0.012 & 0.016 & 0.006 & 0.089 & 0.035 & 0.004 & 0.007 & 0.005 \\
\hline \multirow[t]{4}{*}{$J_{2}$} & DI & 0.552 & 0.428 & 0.257 & 1.861 & 1.197 & 0.361 & 0.260 & 0.855 \\
\hline & IB & 0.340 & 0.251 & 0.173 & 1.449 & 0.682 & 0.310 & 0.210 & 0.657 \\
\hline & $\mathrm{CO}$ & 0.795 & 0.664 & 0.348 & 2.691 & 1.517 & 0.654 & 0.505 & 1.300 \\
\hline & GA-FLC & 0.735 & 0.545 & 0.360 & 1.956 & 1.375 & 0.734 & 0.509 & 1.480 \\
\hline \multirow[t]{4}{*}{$J_{3}$} & DI & 0.103 & 0.082 & 0.054 & 0.375 & 0.179 & 0.048 & 0.075 & 0.075 \\
\hline & IB & 0.114 & 0.137 & 0.065 & 0.559 & 0.341 & 0.051 & 0.079 & 0.092 \\
\hline & $\mathrm{CO}$ & 0.057 & 0.059 & 0.017 & 0.506 & 0.162 & 0.015 & 0.053 & 0.028 \\
\hline & GA-FLC & 0.042 & 0.039 & 0.013 & 0.226 & 0.107 & 0.010 & 0.040 & 0.019 \\
\hline \multirow[t]{4}{*}{$J_{4}$} & DI & 4.542 & 3.400 & 2.099 & 15.063 & 11.038 & 2.145 & 2.059 & 5.072 \\
\hline & IB & 3.253 & 2.527 & 1.725 & 8.230 & 6.735 & 2.777 & 1.981 & 4.492 \\
\hline & $\mathrm{CO}$ & 5.598 & 5.272 & 2.506 & 24.124 & 12.197 & 3.575 & 4.073 & 7.651 \\
\hline & GA-FLC & 5.421 & 4.579 & 2.444 & 12.703 & 11.132 & 4.260 & 3.998 & 9.270 \\
\hline \multirow[t]{4}{*}{$J_{5}$} & DI & 2.802 & 1.950 & 1.277 & 8.671 & 5.262 & 1.677 & 1.332 & 3.992 \\
\hline & IB & 1.436 & 1.116 & 0.770 & 6.608 & 2.807 & 1.523 & 0.892 & 3.034 \\
\hline & $\mathrm{CO}$ & 3.567 & 2.895 & 1.530 & 12.376 & 6.814 & 3.063 & 2.123 & 6.139 \\
\hline & GA-FLC & 3.336 & 2.461 & 1.614 & 9.712 & 6.095 & 3.400 & 2.280 & 6.869 \\
\hline \multirow[t]{4}{*}{$J_{6}$} & DI & 0.687 & 0.871 & 0.336 & 2.761 & 1.915 & 0.471 & 0.422 & 1.035 \\
\hline & IB & 0.581 & 0.466 & 0.241 & 1.587 & 0.983 & 0.362 & 0.381 & 0.779 \\
\hline & $\mathrm{CO}$ & 1.080 & 0.888 & 0.444 & 4.401 & 2.263 & 0.678 & 0.784 & 1.435 \\
\hline & GA-FLC & 0.862 & 0.670 & 0.407 & 2.676 & 1.810 & 0.780 & 0.664 & 1.610 \\
\hline \multirow[t]{4}{*}{$J_{7}$} & DI & 327 & 336 & 214 & 912 & 379 & 115 & 199 & 118 \\
\hline & IB & 129 & 166 & 127 & 512 & 204 & 92 & 142 & 91 \\
\hline & $\mathrm{CO}$ & 320 & 427 & 255 & 823 & 362 & 220 & 314 & 219 \\
\hline & GA-FLC & 321 & 361 & 284 & 742 & 393 & 241 & 383 & 238 \\
\hline \multirow[t]{4}{*}{$J_{8}$} & DI & 2 & 2 & 2 & 2 & 2 & 2 & 2 & 2 \\
\hline & IB & 0.02 & 0.03 & 0.041 & 0.27 & 0.43 & 0.01 & 0.19 & 0.01 \\
\hline & $\mathrm{CO}$ & 2 & 2 & 2 & 2 & 2 & 2 & 2 & 2 \\
\hline & GA-FLC & 0.13 & 0.18 & 0.07 & 0.49 & 0.21 & 0.021 & 0.19 & 0.02 \\
\hline
\end{tabular}

It should be noted that the isolator displacement is reduced by the clipped optimal algorithm better than by the other controller. This large decrease in the isolator displacement has increased the isolator accelerations. This is one of the drawback of the clipped optimal strategy. As there is no variable voltage input between zero and maximum to the MR damper, the damper provides a force to the system which is not optimal.

As shown by the performance index $J_{7}$, the maximum control force (in newtons) is provided by the clipped optimal case in most of the seismic excitations. Performance index $J_{8}$ shows the corresponding maximum voltage supplied to the MR damper in volts.

Similar performance as discussed above for all four control schemes can be observed in the $\mathrm{L}_{2}$ norm responses tabulated in table 4.

From the above discussions, it can be concluded that the performances of all the controllers are a trade-off between the isolator displacement and the superstructure acceleration. A control designer has to select a control scheme based on the priority of the project. As an example, base isolators are provided with an intention to minimize the superstructure displacement and acceleration responses, such that instruments housed inside remain safe during seismic motions. Therefore reducing the base displacement to the full range of the MR damper disrupts the primary intention with which base isolation is provided. Therefore a trade-off has to be made between the acceptable base displacement and acceptable isolator accelerations.

In such a scenario, a designer can allow a certain free movement to the isolator without damping, and after a certain limit the damper should act such that the total displacement should not go beyond the acceptable limit of base displacement. The free movement of the isolator will keep the superstructure and isolator responses at a lower value, and the damper action beyond a certain limit, on the other hand, will minimize the base displacement slightly. This objective is seen to be achieved by both the dynamic inversion based controller and the integrator backstepping based controller.

\section{Conclusion}

In this paper, two model based control algorithms have been developed to monitor the voltage input to an MR damper, such that the desirable performance of the structural system can be achieved. The novelty in the models is that they consider for the first time the effect of the supplied voltage on the commanded voltage dynamics of the MR damper. 
Table 4. Response norms of hybrid base isolated building for $X$-direction (seismic fault parallel component) seismic motion.

\begin{tabular}{|c|c|c|c|c|c|c|c|c|c|}
\hline PI & Control & \multicolumn{8}{|c|}{ Earthquake records } \\
\hline & IB & 0.016 & 0.024 & 0.015 & 0.122 & 0.067 & 0.019 & 0.033 & 0.032 \\
\hline & $\mathrm{CO}$ & 0.006 & 0.046 & 0.008 & 0.075 & 0.029 & 0.003 & 0.010 & 0.002 \\
\hline & GA-FLC & 0.004 & 0.016 & 0.007 & 0.054 & 0.023 & 0.006 & 0.009 & 0.003 \\
\hline & IB & 0.156 & 0.137 & 0.090 & 0.658 & 0.457 & 0.243 & 0.123 & 0.346 \\
\hline & $\mathrm{CO}$ & 0.255 & 0.206 & 0.113 & 1.000 & 0.810 & 0.303 & 0.193 & 0.451 \\
\hline & GA-FLC & 0.292 & 0.220 & 0.127 & 1.122 & 0.874 & 0.376 & 0.212 & 0.515 \\
\hline \multirow[t]{2}{*}{$J_{11}$} & DI & 0.015 & 0.016 & 0.010 & 0.145 & 0.060 & 0.014 & 0.024 & 0.009 \\
\hline & IB & 0.020 & 0.029 & 0.013 & 0.230 & 0.092 & 0.016 & 0.032 & 0.010 \\
\hline & IB & 1.015 & 0.781 & 0.444 & 3.106 & 2.915 & 1.229 & 0.669 & 1.944 \\
\hline & $\mathrm{CO}$ & 1.876 & 1.355 & 0.664 & 7.788 & 6.019 & 1.869 & 1.324 & 2.956 \\
\hline & GA-FLC & 2.120 & 1.392 & 0.799 & 6.139 & 6.103 & 2.556 & 1.445 & 3.587 \\
\hline \multirow[t]{4}{*}{$J_{13}$} & DI & 0.794 & 0.761 & 0.435 & 3.630 & 2.583 & 1.176 & 0.609 & 1.643 \\
\hline & IB & 0.713 & 0.625 & 0.417 & 2.989 & 2.089 & 1.131 & 0.576 & 1.618 \\
\hline & $\mathrm{CO}$ & 1.172 & 0.989 & 0.526 & 4.581 & 3.732 & 1.406 & 0.891 & 2.085 \\
\hline & GA-FLC & 1.345 & 1.021 & 0.589 & 5.216 & 4.024 & 1.737 & 0.980 & 2.374 \\
\hline \multirow[t]{4}{*}{$J_{14}$} & DI & 0.189 & 0.218 & 0.099 & 0.914 & 0.648 & 0.258 & 0.143 & 0.383 \\
\hline & IB & 0.174 & 0.152 & 0.095 & 0.717 & 0.519 & 0.256 & 0.134 & 0.370 \\
\hline & $\mathrm{CO}$ & 0.292 & 0.240 & 0.122 & 1.288 & 0.946 & 0.328 & 0.217 & 0.496 \\
\hline & GA-FLC & 0.322 & 0.237 & 0.136 & 1.206 & 0.961 & 0.407 & 0.232 & 0.560 \\
\hline
\end{tabular}

Furthermore, unlike other model based control algorithms, the proposed algorithms do not switch between zero and maximum voltage values, and as a consequence they provide all voltages within zero and the maximum allowed as an input to the damper.

A motivating example of a three-storey hybrid base isolation is reported. Hybrid base isolation with MR dampers as supplemental damping devices is the current focus of research in structural control technology. A comparison with the widely used clipped optimal and optimal FLCs has been shown. From the results reported, it can be concluded that the performance of the proposed controllers are better than those from the widely used clipped optimal and optimal FLCs. Both clipped optimal and optimal FLCs decrease the isolator displacement but at the cost of an increase in superstructure acceleration. The dynamic inversion and the integrator backstepping based controllers provide a tradeoff between the isolator displacement and superstructure acceleration responses, offering the engineer a suite of options for selecting a design.

\section{References}

[1] Soong T T and Spencer B F 2002 Supplemental energy dissipation: state of the art and state of the practice Eng. Struct. 24 243-59

[2] Dyke S J, Spencer B F Jr, Sain M K and Carlson J D 1996 Modeling and control of magnetorheological dampers for seismic response reduction Smart Mater. Struct. 5 565-75

[3] Ali Sk F and Ramaswamy A 2008 GA optimized FLC driven semi-active control for phase II smart nonlinear base isolated benchmark building Struct. Control Health Monit. $15797-820$
[4] Karnopp D C, Crosby M J and Harwood R A 1974 Vibration control using semi-active force generators J. Eng. Indust. 96 $619-26$

[5] Jung H J, Choi K M, Spencer B F Jr and Lee I W 2005 Application of some semi-active control algorithms to a smart base-isolated building employing MR dampers Struct. Control Health Monit. 13 693-704

[6] Shook D, Lin P Y, Lin T K and Roschke P N 2007 A comparative study in the semi-active control of isolated structures Smart Mater. Struct. 16 1433-46

[7] Feng Q and Shinozuka M 1990 Use of a variable damper for hybrid control of bridge response under earthquake Proc. US National Workshop on Structural Control Research (Univ. of Southern California, Los Angeles) ed G Housner and S Masri, pp 107-12, USC Publication No. CE-9013

[8] Leitmann G 1994 Semi-active control for vibration attenuation J. Intell. Mater. Syst. Struct. 5 841-6

[9] Sahasrabudhe S and Nagarajaiah S 2005 Experimental study of sliding base-isolated building with magnetorheological dampers in near fault earthquakes J. Struct. Eng., ASCE 131 1025-34

[10] Xu Z D, Shen Y P and Guo Y Q 2003 Semi-active control of structures incorporated with magnetorheological dampers using neural-networks Smart Mater. Struct. 12 80-7

[11] Ali Sk F 2008 Semi-active control of earthquake induced vibrations in structures using MR dampers: algorithm development, experimental verification and benchmark applications $P h D$ Thesis Indian Institute of Science, Bangalore, India

[12] Yang G, Spencer B F, Jung H H and Carlson J D Jr 2004 Dynamic modeling of large-scale magnetorheological damper systems for Civil Engineering applications J. Eng. Mech., ASCE 130 1107-14

[13] Wereley N M and Pang L 1998 Nondimensional analysis of semi-active electrorheological and magnetorheological dampers using approximate parallel plate models Smart Mater. Struct. 7 732-43

[14] MR Dampers 2006 LORD Technical Data: RD-1005 Damper http://www.lordfulfillment.com/upload/DS7017.pdf 
[15] Spencer B F Jr, Dyke S J, Sain M K and Carlson J D 1997 Phenomenological model for magnetorheological dampers J. Eng. Mech., ASCE 123 230-8

[16] Ali Sk F and Ramaswamy A 2009 Testing and modeling of MR damper and its application to SDOF systems using integral backstepping technique Trans. ASME J. Dyn. Syst. Meas. Control 131021009

[17] MATLAB 2004 The Software for Numerical Computing, Version 7.0.1 (R 14) The MathWorks http://www. mathworks.com/index.html?ref=pt

[18] Jansen L M and Dyke S J 1999 Investigation of nonlinear control strategies for the implementation of multiple magnetorheological dampers 1999 ASCE Engineering Mechanics Conf. (Baltimore, MD, June)

[19] Jansen L M and Dyke S J 2000 Semiactive control strategies for MR dampers: comparative study J. Eng. Mech., ASCE $126795-803$

[20] Ali Sk F and Ramaswamy A 2008 Optimal fuzzy logic control for MDOF structural systems using evolutionary algorithms
Eng. Appl. Artif. Intell., IFAC

doi:10.1016/j.engappai.2008.09.004

[21] Reiner J, Balas G J and Garrard W L 1995 Robust dynamic inversion for control of highly maneuverable aircraft J. Guid., Control, Dyn. 18 18-24

[22] Márquez H J 2003 Nonlinear Control Systems: Analysis and Design (New York: Wiley Interscience)

[23] Ali Sk F and Ramaswamy A 2009 Optimal dynamic inversion based semi-active control of benchmark bridge using MR dampers Struct. Control Health Monit. at press (doi:10.1002/stc.325)

[24] Krstic M, Kanellakopoulos I and Kokotovic P V 1995 Nonlinear and Adaptive Control Design (New York: Wiley)

[25] Krstic M and Smyshlyaev A 2007 Backstepping boundary control-a tutorial Proc. American Control Conf. (New York City, NY, July) pp 870-5

[26] Chopra A K 2005 Dynamics of Structures: Theory and Application to Earthquake Engineering (New Delhi: Pearson Education) 